\title{
Changes in regional meteorology induced by anthropogenic heat and their impacts on air quality in South China
}

\author{
Min Xie ${ }^{1,2,3}$, Kuanguang Zhu ${ }^{1,5}$, Tijian Wang ${ }^{1,3,4}$, Wen Feng ${ }^{2}$, Da Gao ${ }^{1}$, Mengmeng Li ${ }^{1}$, Shu Li ${ }^{1}$, Bingliang Zhuang ${ }^{1,3}$, \\ Yong Han ${ }^{1}$, Pulong Chen ${ }^{1}$, and Jingbiao Liao ${ }^{1}$ \\ ${ }^{1}$ School of Atmospheric Sciences, Nanjing University, Nanjing, China \\ ${ }^{2}$ Key Laboratory of South China Sea Meteorological Disaster Prevention and Mitigation of Hainan Province, Haikou, China \\ ${ }^{3}$ Jiangsu Collaborative Innovation Center for Climate Change, Nanjing, China \\ ${ }^{4}$ CMA-NJU Joint Laboratory for Climate Prediction Studies, Institute for Climate and Global Change Research, \\ School of Atmospheric Sciences, Nanjing University, Nanjing, China \\ ${ }^{5}$ Hubei Academy of Environmental Sciences, Wuhan, China
}

Correspondence to: Min Xie (minxie@nju.edu.cn) and Tijian Wang (tjwang@ nju.edu.cn)

Received: 21 June 2016 - Published in Atmos. Chem. Phys. Discuss.: 5 July 2016

Revised: 28 October 2016 - Accepted: 17 November 2016 - Published: 6 December 2016

\begin{abstract}
Anthropogenic heat (AH) emissions from human activities can change the urban circulation and thereby affect the air pollution in and around cities. Based on statistic data, the spatial distribution of AH flux in South China is estimated. With the aid of the Weather Research and Forecasting model coupled with Chemistry (WRF/Chem), in which the AH parameterization is developed to incorporate the gridded AH emissions with temporal variation, simulations for January and July in 2014 are performed over South China. By analyzing the differences between the simulations with and without adding $\mathrm{AH}$, the impact of $\mathrm{AH}$ on regional meteorology and air quality is quantified. The results show that the regional annual mean AH fluxes over South China are only $0.87 \mathrm{~W} \mathrm{~m}^{-2}$, but the values for the urban areas of the Pearl River Delta (PRD) region can be close to $60 \mathrm{~W} \mathrm{~m}^{-2}$. These AH emissions can significantly change the urban heat island and urban-breeze circulations in big cities. In the PRD city cluster, $2 \mathrm{~m}$ air temperature rises by $1.1^{\circ}$ in January and over $0.5^{\circ}$ in July, the planetary boundary layer height (PBLH) increases by $120 \mathrm{~m}$ in January and $90 \mathrm{~m}$ in July, $10 \mathrm{~m}$ wind speed is intensified to over $0.35 \mathrm{~m} \mathrm{~s}^{-1}$ in January and $0.3 \mathrm{~m} \mathrm{~s}^{-1}$ in July, and accumulative precipitation is enhanced by $20-40 \%$ in July. These changes in meteorological conditions can significantly impact the spatial and vertical distributions of air pollutants. Due to the increases in PBLH, surface wind speed and upward vertical movement, the concentrations of primary air pollutants decrease near the sur-
\end{abstract}

face and increase in the upper levels. But the vertical changes in $\mathrm{O}_{3}$ concentrations show the different patterns in different seasons. The surface $\mathrm{O}_{3}$ concentrations in big cities increase with maximum values of over $2.5 \mathrm{ppb}$ in January, while $\mathrm{O}_{3}$ is reduced at the lower layers and increases at the upper layers above some megacities in July. This phenomenon can be attributed to the fact that chemical effects can play a significant role in $\mathrm{O}_{3}$ changes over South China in winter, while the vertical movement can be the dominant effect in some big cities in summer. Adding the gridded $\mathrm{AH}$ emissions can better describe the heterogeneous impacts of $\mathrm{AH}$ on regional meteorology and air quality, suggesting that more studies on AH should be carried out in climate and air quality assessments.

\section{Introduction}

Urbanization and its impacts on regional meteorology and air quality have been widely acknowledged, observed and investigated (Rizwan et al., 2008; Mirzaei and Haghighat, 2010). Previous studies have illustrated that urbanization can affect the atmospheric environment in many ways, which are mainly associated with the increase in air pollutant emissions from the intensification of energy consumption (Akbari et al., 2001; Civerolo et al., 2007; Jiang et al., 2008; Stone, 2008; Chen et al., 2014b), the change in land cover from natural 
surfaces to artificial ones (Civerolo et al., 2007; Lo et al., 2007; Wang et al., 2007; X. M. Wang, 2009; Jiang et al., 2008; D. L. Zhang et al., 2009; Lu et al., 2010; Wu et al., 2011; Chen et al., 2014b; Liao et al., 2015; Zhu et al., 2015; $\mathrm{Li}$ et al., 2016) and the release of anthropogenic heat from human activities in cities (Ryu et al., 2013; Yu et al., 2014; Xie et al., 2016). Anthropogenic heat (AH) can increase turbulent fluxes in sensible and latent heat (Oke, 1988), implying that it can modulate local and regional meteorological processes (Ichinose et al., 1999; Block et al., 2004; Fan and Sailor, 2005; Ferguson and Woodbury, 2007; Chen et al., 2009; Zhu et al., 2010; Feng et al., 2012, 2014; Menberg et al., 2013; Ryu et al., 2013; Wu and Yang, 2013; Bohnenstengel et al., 2014; Chen et al., 2014a; Meng et al., 2011; Yu et al., 2014; Xie et al., 2016) and thereby exert an important influence on the formation and the distribution of ozone (Ryu et al., 2013; Yu et al., 2014; Xie et al., 2016) as well as aerosols (Yu et al., 2014; Xie et al., 2016).

Previous studies on AH basically focused on the amount of heat fluxes or their effects on meteorology. It was reported that the typical values of AH fluxes in urban areas range from 20 to $100 \mathrm{~W} \mathrm{~m}^{-2}$ (Crutzen, 2004; Sailor and Lu, 2004; Fan and Sailor, 2005; Pigeon et al., 2007; Lee et al., 2009; Iamarino et al., 2012; Lu et al., 2016; Xie et al., 2016). Sometimes, the fluxes might exceed the value of $100 \mathrm{~W} \mathrm{~m}^{-2}$ (Iamarino et al., 2012; Quah and Roth, 2012; Lu et al., 2016; Xie et al., 2016), with the extreme value of $1590 \mathrm{~W} \mathrm{~m}^{-2}$ in the densest part of Tokyo at the peak of air-conditioning demand (Ichinose et al., 1999). With regard to their effects, the researchers found that AH fluxes can cause urban air temperatures to increase by several degrees (Fan and Sailor, 2005; Ferguson and Woodbury, 2007; Zhu et al., 2010; Feng et al., 2012, 2014; Menberg et al., 2013; Wu and Yang, 2013; Bohnenstengel et al., 2014; Chen et al., 2009, 2014a; Yu et al., 2014; Xie et al., 2016), induce the atmosphere to be more turbulent and unstable, change the urban heat island circulation, strengthen vertical air movement (Ichinose et al., 1999; Block et al., 2004; Fan and Sailor, 2005; Chen et al., 2009; Feng et al., 2012, 2014; Bohnenstengel et al., 2014; Yu et al., 2014; Xie et al., 2016), enhance the convergence of water vapor in cities, and change the regional precipitation patterns (Feng et al., 2012, 2014; Xie et al., 2016). In spite of meteorology conditions and air quality being inextricably linked, however, few investigations have paid attention to how the air quality is altered by the changes in regional meteorology induced by anthropogenic heat. The results from the limited studies have shown that this impact is significant in and around large urban areas and should be considered in air pollution predictions (Ryu et al., 2013; Yu et al., 2014; Xie et al., 2016).

Over the past decades, South China has been suffering from air quality deterioration (Wang et al., 2007; X. M. Wang, 2009; Chan and Yao, 2008; Q. Liu et al., 2013), with high ozone $\left(\mathrm{O}_{3}\right)$ or poor visibility frequently occurring in urban areas (Wang et al., 2007; Fang et al., 2009) and the background air pollutant concentrations steadily increasing (T. Wang et al., 2009; Q. Liu et al., 2013). South China generally refers to Guangdong, Guangxi, Hainan, Hong Kong and Macau. The main feature of the terrain is mountainous and hilly. The majority of South China has a humid subtropical climate. Winters are mild, while summers are hot and muggy. It faces the South China Sea to the south and has the longest coastline in China, so there are many islands in South China, including Hainan Island. These coastal areas can be influenced by both the monsoon and the dangerous typhoon. The air pollution in South China may be related to the rapid urban expansion, especially in the Pearl River Delta (PRD) region. The PRD region consists of nine cities in Guangdong Province (Guangzhou, Shenzhen, Zhuhai, Dongguan, Zhongshan, Foshan, Jiangmen, Huizhou and Zhaoqing) plus Hong Kong and Macau (shown in the green square of Fig. 1b). As the most urbanized and industrialized part of South China, PRD has become the largest metropolitan area in the world within a very short time (Word Bank Group, 2015). Thus, many previous studies have tried to identify the effects of urbanization on urban climate and air quality in this region (Lo et al., 2007; Wang et al., 2007; X. M. Wang, 2009; Lu et al., 2010; Meng et al., 2011; Wu et al., 2011; Zhang et al., 2011; Feng et al., 2012, 2014; Chen et al., 2014b; Li et al., 2014, 2016). Among these studies, most researchers merely investigated how the expansion of urban land use influences meteorology processes (Lo et al., 2007; Wang et al., 2007; X. M. Wang, 2009; Lu et al., 2010; Meng et al., 2011; Wu et al., 2011; Feng et al., 2012; Chen et al., 2014b; Li et al., 2016). Some also linked these changes in meteorological factors with regional air quality and quantified the impacts of land-use change on air pollution (Wang et al., 2007; X. M. Wang, 2009; Feng et al., 2012; Chen et al., 2014b; Li et al., 2014, 2016). Only a few researchers took AH into account (Meng et al., 2011; Feng et al., 2012, 2014). But they just clarified the impact of $\mathrm{AH}$ on meteorological conditions by merely adopting the fixed AH value in the urban parameterization scheme of meteorological models (Meng et al., 2011; Feng et al., 2012). Consequently, we still need to further understand how the excessive anthropogenic heat from urban expansion impacts on the severe air quality problems in this world-famous region.

To fill the abovementioned knowledge gap, we present our new findings on the impact mechanism of anthropogenic heat regarding urban climate and regional air quality over South China in this paper, including (1) the spatial and temporal characteristics of AH emissions in South China, (2) how to implement the inhomogeneous $\mathrm{AH}$ data into the air quality model WRF/Chem (Weather Research and Forecasting model coupled with Chemistry), (3) the impacts of AH fluxes on meteorological fields, and (4) the impacts of meteorology changes on the air quality in different cities in South China. Detailed descriptions about the estimating method for anthropogenic heat emissions, the adopted WRF/Chem model with special configurations and the observation data 


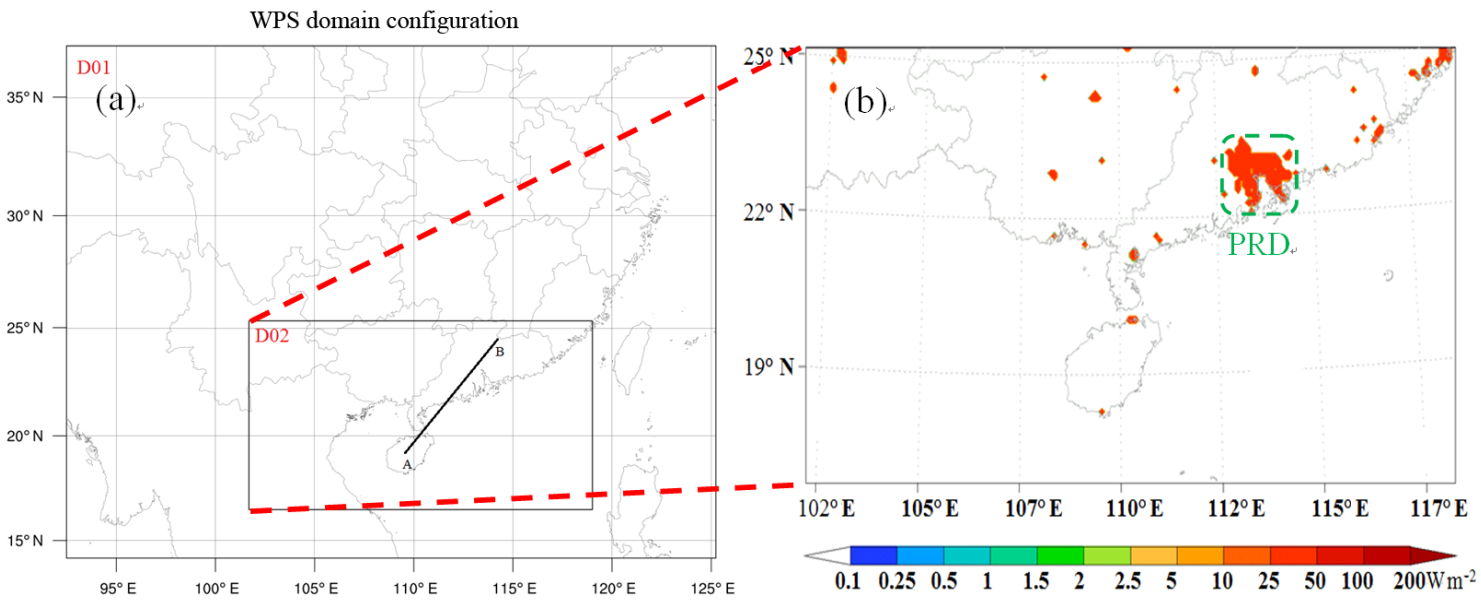

Figure 1. WRF/Chem domain configuration, including (a) two domains for simulations and (b) enlarged view of domain 2 with fixed AH value of $50 \mathrm{~W} \mathrm{~m}^{-2}$ for all urban grids used in the simulation case Fix_AH. Line AB in (a) denotes the location of the vertical cross section used in Figs. 4, 6, 8, 9 and 10. The green square in (b) presents the location of the Pearl River Delta (PRD) region.

for model validation are presented in Sect. 2. Main results, including the inhomogeneous distribution of $\mathrm{AH}$, the model evaluation, and the three-dimensional changes in meteorological fields and air pollutant concentrations are presented in Sect. 3. The summary is given in Sect. 4.

\section{Methodology and data}

\subsection{Method for estimating anthropogenic heat fluxes}

The top-down energy inventory method, which predicts $\mathrm{AH}$ emissions based on the statistics data of energy consumption, is the most common approach and widely used all over the world (Sailor and Lu, 2004; Flanner, 2009; Hamilton et al., 2009; Lee et al., 2009; Allen et al., 2011; Iamarino et al., 2012; Quah and Roth, 2012; Chen et al., 2014a) as well as in China (Chen et al., 2012; Xie et al., 2015, 2016; Lu et al., 2016). On the basis of the previous studies, AH fluxes over the area between $\left(101^{\circ} \mathrm{E}, 16^{\circ} \mathrm{N}\right)$ and $\left(119^{\circ} \mathrm{E}, 26^{\circ} \mathrm{N}\right)$ in 1990, 1995, 2000, 2005, 2010 and 2014 are calculated in this study by the following equation:

$Q_{\mathrm{F}}=Q_{\mathrm{F}, \mathrm{I}}+Q_{\mathrm{F}, \mathrm{B}}+Q_{\mathrm{F}, \mathrm{V}}+Q_{\mathrm{F}, \mathrm{HM}}$,

where $Q_{\mathrm{F}}$ is the total anthropogenic heat flux $\left(\mathrm{W} \mathrm{m}^{-2}\right) ; Q_{\mathrm{F}, \mathrm{I}}$, $Q_{\mathrm{F}, \mathrm{B}}, Q_{\mathrm{F}, \mathrm{V}}$ and $Q_{\mathrm{F}, \mathrm{HM}}$ represent the heat emitted from the industry sector, buildings, vehicles and human metabolism $\left(\mathrm{W} \mathrm{m}^{-2}\right)$, respectively. To accurately estimate the spatial heterogeneity of AH fluxes, the estimated area is gridded as 456 rows and 264 columns with a grid spacing of $2.5 \mathrm{arcmin}$. The heat flux generated by human metabolism at each grid is estimated as:

$Q_{\mathrm{F}, \mathrm{HM}}=P \cdot\left(M_{\mathrm{d}} \cdot h_{\mathrm{d}}+M_{\mathrm{n}} \cdot h_{\mathrm{n}}\right) / h$, where $P$ is the population number at a grid. $h_{\mathrm{d}}, h_{\mathrm{n}}$ and $h$ are the hours of daytime, nighttime and a whole day. In this study, they are set to be 16,8 and 24 , respectively. $M_{\mathrm{d}}$ and $M_{\mathrm{n}}$ are the average human metabolic rate $\left(\mathrm{W}\right.$ person $\left.{ }^{-1}\right)$ during the daytime and at night. Referring to the previous studies (Sailor and Lu, 2004; Chen et al., 2012; Quah and Roth, 2012; Xie et al., 2015, 2016; Lu et al., 2016), we determined that the metabolic rate of a typical man is $175 \mathrm{~W}$ for the active daytime $\left(M_{\mathrm{d}}\right)$ and $75 \mathrm{~W}$ for the sleep period $\left(M_{\mathrm{n}}\right)$.

Based on the work of Flanner (2009), Lu et al. (2016) and Xie et al. (2016), it is reasonably assumed that all nonrenewable primary energy consumption used for human activities is thermally dissipated as AH. So, $Q_{\mathrm{F}, \mathrm{I}}, Q_{\mathrm{F}, \mathrm{B}}$ and $Q_{\mathrm{F}, \mathrm{V}}$ at each grid can be estimated by using the data of nonrenewable energy consumption (coal, petroleum, natural gas and electricity, etc.) from different categories. The amount of $\mathrm{AH}$ fluxes for one category can be estimated by the following equation:

$Q_{x}=\eta \cdot \varepsilon \cdot C /(t \cdot A)$,

where $Q_{x}$ represents $Q_{\mathrm{F}, \mathrm{I}}, Q_{\mathrm{F}, \mathrm{B}}$ or $Q_{\mathrm{F}, \mathrm{V}} . C$ is the primary energy consumption from a category at a grid (metric ton standard coal). $\varepsilon$ is the calorific value of standard coal equivalent, with the recommended value of $29.271 \times 10^{3} \mathrm{~kJ} \mathrm{~kg}^{-1}$ (Chen et al., 2012; Lu et al., 2016; Xie et al., 2015, 2016). $\eta$ is the efficiency of heat release, with a typical value of $60 \%$ for the electricity or heat-supply sector and $100 \%$ for other sectors (Lu et al., 2016; Xie et al., 2016). $t$ is the time duration of the data used, which is set to be $31536000 \mathrm{~s}$ (seconds in a year) in this study. $A$ represents the area of a grid $\left(\mathrm{km}^{2}\right)$. To quantify the value of $C$ for each grid, we first of all obtain the energy consumption data from 1990 to 2014 in China Energy Statistical Yearbooks. Then we double-check and modify the data in typical cities on the basis of the yearbooks in Guangdong, Guangxi, Hainan province and Hong Kong. In the end, 
the total numbers are apportioned according to the value of gross domestic product (GDP) or population density at each grid. GDP is used for industry and vehicles, while population is chosen for buildings. The population density with a resolution of 2.5 arcmin in 1990, 1995, 2000, 2005 and 2010 can be downloaded from Columbia University's Socioeconomic Data and Applications Center. The gridded GDP data are developed and applied based on the work of M. Liu et al. (2013). The spatial distributions of GDP and population in 2014 are unobtainable, and therefore the data in 2010 are used as surrogates.

\subsection{WRF/Chem and its configuration}

The WRF/Chem version 3.5 is applied to investigate the impacts of AH fluxes on regional meteorology and air quality over South China. WRF/Chem is a new generation of air quality modeling system, in which the feedbacks between meteorology and air pollutants are included by fully coupling the meteorological model (WRF) with the chemical modules (Chem). WRF/Chem has been widely used in simulating air quality in China and proved to be a reliable modeling tool from the city scale to the mesoscale (X. M. Wang et al., 2009; Q. Liu et al., 2013; Yu et al., 2014; Liao et al., 2015; Xie et al., 2016).

Three simulations are conducted in this study. One does not take the contribution of AH into account, while the other two incorporate WRF/Chem with fixed or inhomogeneous AH fluxes (the details are presented in Sect. 2.3). Except for the setting of AH parameterization, other configurations (such as the physical schemes, the chemical schemes and the emission inventories etc.) for all simulations are the same. Thus, the difference between the modeling results can illustrate the effects of AH. As shown in Fig. 1, two nested domains are used. The outermost domain (Domain 1, D01) has horizontal grids of $121 \times 95$, with a grid spacing of $27 \mathrm{~km}$. The second domain (Domain 2, D02) covers Guangdong, Guangxi and Hainan provinces, with the center point at $\left(110.4^{\circ} \mathrm{E}, 20.9^{\circ} \mathrm{N}\right)$, horizontal grids of $192 \times 105$, and a grid spacing of $9 \mathrm{~km}$. For all domains, from the ground level to the top pressure of $100 \mathrm{hPa}$, there are 31 vertical sigma layers with about 10 in the planetary boundary layer (PBL). In South China, January is generally representative of the relatively cold and dry season, while July represents the relatively hot and wet weather conditions (Wang et al., 2014). Thus, January and July of 2014 are chosen for simulations and analysis in this study.

The detailed options for the physical and chemical parameterization schemes used in this study are shown in Table 1. Additionally, a Single Layer Urban Canopy Model (SLUCM) coupled to the Noah land surface model (Noah/LSM) is adopted for a better modeling of the urban effects. Following the work of Q. Liu et al. (2013) and Wang et al. (2014), the default values for urban canopy parameters in SLUCM are substituted by the typical values in South
Table 1. The grid settings, physics and chemistry options for all simulations.

\begin{tabular}{ll}
\hline Items & Contents \\
\hline Dimensions $(x, y)$ & $(121,95),(192,105)$ \\
Grid size $(\mathrm{km})$ & 27,9 \\
Time step (s) & 150 \\
Microphysics & $\begin{array}{l}\text { Purdue Lin microphysics scheme (Lin } \\
\text { et al., 1983) }\end{array}$ \\
Long-wave radiation & RRTM scheme (Mlawer et al., 1997) \\
Shortwave radiation & Goddard scheme (Kim and Wang, 2011) \\
Cumulus parameterization & Grell 3-D (Grell and Devenyi, 2002) \\
Surface layer & Eta similarity (Janjic, 1994) \\
Land surface & Noah land surface model (Chen and Dudhia, \\
& 2001) \\
Planetary boundary layer & Mellor-Yamada-Janjic scheme (Janjic, 1994) \\
Gas-phase chemistry & RADM2 (Stockwell et al., 1990) \\
Photolysis scheme & Madronich photolysis (Madronich, 1987) \\
Aerosol module & MADE (Ackermann et al., 1998)/ \\
& SORGAM (Schell et al., 2001) \\
\hline
\end{tabular}

China. As shown in Table 2, the values for building height, roof width, road width, urban fraction and surface albedo are modified for the cities in and outside PRD. The recently updated Moderate Resolution Imaging Spectroradiometer (MODIS) land-use data (20 categories) with 30 arcsec grid spacing are used to replace the default USGS (US Geological Survey) land-use data in WRF/Chem because the USGS data are too outdated to illustrate the intensive urbanization in South China. For chemistry, the RADM2 (Regional Acid Deposition Model version 2) gas-phase chemistry scheme and the MADE/SORGAM aerosol scheme are adopted. RADM2 contains 63 prognostic species and 136 reactions (Balzarini et al., 2015). MADE/SORGAM is the classical aerosol module used in WRF/Chem (Grell et al., 2005), where the Aerosol Dynamics Model for Europe (MADE) (Ackermann et al., 1998) contains the Secondary Organic Aerosol Model (SORGAM) (Schell et al., 2001). The anthropogenic emissions are mainly from the 2012 Multi-resolution Emission Inventory for China (MEIC) with $0.25^{\circ}$ grid spacing. This MEIC inventory based on the RADM2 mechanism is re-projected for the grids of China in both domains. For the grids outside of China, the inventory developed by Q. Zhang et al. (2009) is used. The biomass burning emissions are acquired from the work of $\mathrm{Li}$ et al. (2016). The biogenic emissions are calculated online by using MEGAN2.04 (Model of Emissions of Gases and Aerosols from Nature; Guenther et al., 2006). The NCEP global reanalysis data with a grid spacing of $1^{\circ}$ and 27 vertical levels are selected to provide the initial meteorological fields and boundary conditions. The initial chemical state and boundary conditions are obtained from the modeling results from the global chemistry transport model MOZART-4. 
Table 2. The modified values of the main urban canopy parameters for the PRD region and other cities.

\begin{tabular}{llrr}
\hline Parameter & Unit & PRD & $\begin{array}{r}\text { Other } \\
\text { cities }\end{array}$ \\
\hline Building height & $\mathrm{m}$ & 20 & 10 \\
Roof width & $\mathrm{m}$ & 15 & 10 \\
Road width & $\mathrm{m}$ & 10 & 10 \\
Urban fraction & fraction & 0.95 & 0.9 \\
Surface albedo of roof & fraction & 0.2 & 0.2 \\
Surface albedo of wall & fraction & 0.2 & 0.2 \\
Surface albedo of road & fraction & 0.2 & 0.2 \\
Roughness length for & $\mathrm{m}$ & 0.15 & 0.15 \\
momentum over roof & & & \\
Roughness length for & $\mathrm{m}$ & 0.05 & 0.05 \\
momentum over wall & & & \\
Roughness length for & $\mathrm{m}$ & 0.05 & 0.05 \\
momentum over road & & & \\
\hline
\end{tabular}

\subsection{The configurations for AH parameterization}

As shown in Table 3, three numerical experiments are performed to evaluate the effects of AH. Non_AH is the base case, which does not consider the effects of AH. In Fix_AH, the default option for AH in SLUCM of WRF/Chem is adopted. For Grd_AH, we modify the AH parameterization, and the gridded AH flux data estimated in Sect. 2.1 are used to simulation the spatial heterogeneous effects of $\mathrm{AH}$ on meteorology and air quality. The difference between the modeling results of Fix_AH and Grd_AH can illustrate the model improvement caused by considering the spatial heterogeneity of AH. Comparing the results from Non_AH and Grd_AH, we can finally demonstrate the exact impacts of anthropogenic heat.

In SLUCM of WRF/Chem, the AH for one grid is determined by the fixed AH value, the fixed temporal diurnal pattern and the urban fraction value (Chen et al., 2011; Yu et al., 2014; Xie et al., 2016). This default parameterization for AH can be described by the following algorithm:

$\mathrm{SH}=F_{\mathrm{V}} \cdot \mathrm{SH}_{\mathrm{V}}+F_{\mathrm{U}} \cdot\left(\mathrm{SH}_{\mathrm{U}}+\mathrm{AH}_{\mathrm{fixed}}\right)$,

where $\mathrm{SH}$ is the total sensible heat flux in a grid. $F_{\mathrm{V}}$ and $\mathrm{SH}_{\mathrm{V}}$ are the fractional coverage and the sensible heat flux of vegetation, respectively. $F_{\mathrm{U}}$ and $\mathrm{SH}_{\mathrm{U}}$ are those of urban surfaces. $\mathrm{AH}_{\text {fixed }}$ represents the fixed $\mathrm{AH}$ value for all urban areas (Chen et al., 2011). With respect to Grd_AH, we modify Eq. (4) by incorporating the inhomogeneous $\mathrm{AH}$ data $\left(Q_{\mathrm{F}}\right)$ as follows:

$\mathrm{SH}=F_{\mathrm{V}} \cdot \mathrm{SH}_{\mathrm{V}}+F_{\mathrm{U}} \cdot\left(\mathrm{SH}_{\mathrm{U}}+Q_{\mathrm{F}}\right)$.

The gridded AH fluxes in 2014 from Sect. 2.1 (with a grid spacing of about $4 \mathrm{~km})$ are re-projected to domain $2(9 \mathrm{~km})$ by the coordinates of each grid. To account for temporal variability, the diurnal variation pattern recommended for PRD
Table 3. The three simulations conducted in this study.

\begin{tabular}{ll}
\hline Cases & Description \\
\hline $\begin{array}{l}\text { Non_AH } \\
\text { Fix_AH }\end{array}$ & $\begin{array}{l}\text { excluding anthropogenic heat emissions in SLUCM } \\
\text { including anthropogenic heat emissions in SLUCM but } \\
\text { using the default AH option with fixed value } 50 \mathrm{~W} \mathrm{~m}^{-2} \\
\text { for all urban grids } \\
\text { including anthropogenic heat emissions in SLUCM } \\
\text { and using the inhomogeneous AH emissions in } 2014 \\
\text { estimated in Sect. 2.1 }\end{array}$ \\
Grd_AH
\end{tabular}

by Zheng et al. (2009) and Lu et al. (2016) is adopted. It was reported that there is no significant seasonal difference in heating over South China (Lu et al., 2016). Thus, the monthly variation of $\mathrm{AH}$ is not considered in this study.

\subsection{Method for model evaluation}

The observation data of meteorology factors and air pollutants in Guangzhou, Shenzhen, Nanning and Haikou are used to validate the WRF/Chem simulations in this study. The hourly observation records of $2 \mathrm{~m}$ temperature, $10 \mathrm{~m}$ wind speed and $2 \mathrm{~m}$ relative humidity in January and July of 2014 can be obtained from the National Meteorological Center of China Meteorological Administration. The relevant time series of $\mathrm{PM}_{10}$ and $\mathrm{O}_{3}$ concentrations can be acquired from China National Environmental Monitoring Center. The quality-assurance-quality-control (QA/QC) procedures for these data strictly follow the national standards. As described by Liao et al. (2015) and Xie et al. (2016), the mean bias (MB), root mean square error (RMSE) and correlation coefficient (COR) between observation records and modeling results are used to evaluate the model performance.

\section{Results and discussions}

\subsection{Spatial distribution of AH fluxes in South China}

Figure 2 shows the spatial distribution of AH in 1990, 1995, 2000, 2005, 2010 and 2014 over South China. Obviously, big cities, especially the cities in PRD, have the largest values from the 1990s till now. In 1990, except for those in Guangdong and Hong Kong, the AH fluxes in most areas of South China are less than $2 \mathrm{~W} \mathrm{~m}^{-2}$. From 1995 to 2000, the $\mathrm{AH}$ fluxes in most parts of PRD (except for those in Hong Kong) are less than $5 \mathrm{~W} \mathrm{~m}^{-2}$, and those in other areas of South China are generally lower than $2.5 \mathrm{~W} \mathrm{~m}^{-2}$. After 2005, however, the AH fluxes exceed $10 \mathrm{~W} \mathrm{~m}^{-2}$ in many cities of South China, with high values over $50 \mathrm{~W} \mathrm{~m}^{-2}$ in and around Hong Kong. As for the annual mean AH flux over the whole administrative district of a different province, the value in Guangdong continuously increases from $0.30 \mathrm{~W} \mathrm{~m}^{-2}$ for 1990 to $1.68 \mathrm{~W} \mathrm{~m}^{-2}$ for 2014, while the heat release in Guangxi and Hainan remains at a low level $\left(<0.5 \mathrm{~W} \mathrm{~m}^{-2}\right)$ but with an ob- 

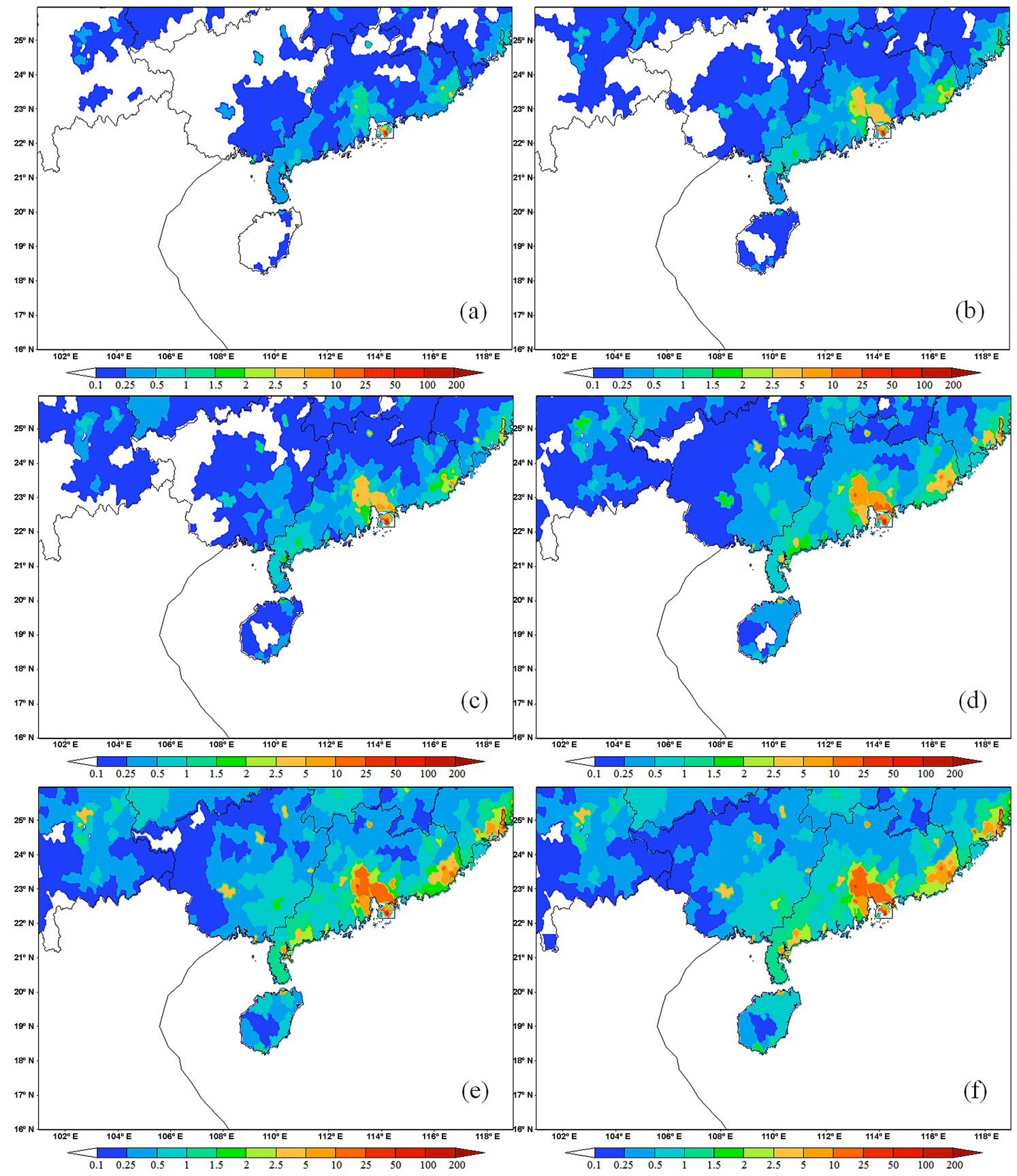

Figure 2. Annual mean anthropogenic heat fluxes between $\left(101^{\circ} \mathrm{E}, 16^{\circ} \mathrm{N}\right)$ and $\left(119^{\circ} \mathrm{E}, 26^{\circ} \mathrm{N}\right)$ with a resolution of 2.5 arcmin in $1990($ a), 1995 (b), 2000 (c), 2005 (d), 2010 (e) and 2014 (f).

vious increase. The annual mean $\mathrm{AH}$ values in the downtown areas are much higher than the regional ones. For instance, the PRD city cluster always has the highest anthropogenic heat emissions in South China. As shown in Table 4, the annual mean value in the built-up areas rises from $5.1 \mathrm{~W} \mathrm{~m}^{-2}$ in 1990 to $58 \mathrm{~W} \mathrm{~m}^{-2}$ in 2014 . These results are similar to those reported by Chen et al. (2012, 2014a) and Xie et al. (2015), and the temporal variation pattern also fits in well with the economic boom in South China in the past decades.

In 2014, as illustrated in Fig. 2f, the most important cities in South China have AH fluxes of more than $5 \mathrm{~W} \mathrm{~m}^{-2}$. High fluxes generally occur in Guangdong province, especially in the PRD region and the Chao-Shan area, with typical values over $10 \mathrm{~W} \mathrm{~m}^{-2}$. In the built-up area of Guangzhou, the AH fluxes are close to $60 \mathrm{~W} \mathrm{~m}^{-2}$, which is similar to those 
in Seoul, Korea (Lee et al., 2009); Toulouse, France (Pigeon et al., 2007); and some US cities (Sailor and Lu, 2004; Fan and Sailor, 2005). The highest regional value occurs in Hong Kong, with the value exceeding $100 \mathrm{~W} \mathrm{~m}^{-2}$. This value is comparable to those in the most crowded megacities, such as Shanghai (Xie et al., 2016), Tokyo (Ichinose et al., 1999), London (Hamilton et al., 2009; Iamarino et al., 2012) and Singapore (Quah and Roth, 2012). In Nanning and Haikou, the annual mean $\mathrm{AH}$ fluxes over the whole administrative district are close to $10 \mathrm{~W} \mathrm{~m}^{-2}$. These results can also be supported by other previous investigations (Flanner, 2009; Chen et al., 2012, 2014a; Xie et al., 2015; Lu et al., 2016). With regard to the default $\mathrm{AH}$ option in WRF/Chem, the fixed value of $50 \mathrm{~W} \mathrm{~m}^{-2}$ is usually used for all urban grids (shown in Fig. 1b). Compared with this unrealistic distribution pattern (Fig. 1b), our spatial distribution of AH based on the population (Fig. 2f) reflects the heterogeneity of economic activities in South China, suggesting that our method is effective and the results are reasonable. So, our AH data can be used in models to investigate their impacts on urban climate and air quality.

\subsection{Simulation performance}

To evaluate the model performance and clarify the better AH parameterization, the modeling results from Fix_AH and Grd_AH are compared with the observation data in two typical months (January and July). Table 5 presents the performance statistics, including the values of monthly mean (Mean), mean bias (MB), root mean squared error (RMSE) and correlative coefficient (COR), which are all quantified for $2 \mathrm{~m}$ temperature $\left(T_{2}\right), 2 \mathrm{~m}$ relative humidity $\left(\mathrm{RH}_{2}\right), 10 \mathrm{~m}$ wind speed $\left(\mathrm{WS}_{10}\right)$, ozone $\left(\mathrm{O}_{3}\right)$ and particles $\left(\mathrm{PM}_{10}\right)$ in Guangzhou (GZ), Shenzhen (SZ), Nanning (NN) and Haikou (HK).

As shown in Table 5, the correlation coefficients (COR) between observations and simulations at the four sites are generally about 0.80 for $T_{2}$, over 0.75 for $\mathrm{RH}_{2}$ and close to 0.70 for $\mathrm{WS}_{10}$ in both January and July (statistically significant at the $95 \%$ confident level). So, adding $\mathrm{AH}$ in WRF/Chem (Fix_AH and Grd_AH) can describe the urban meteorological conditions over the typical cities in South China well. Compared with the observation records of $T_{2}$, except for Shenzhen in January, both Fix_AH and Grd_AH tend to slightly simulate higher $2 \mathrm{~m}$ air temperature at the four sites in both months, which can be attributed to the uncertainty of urban canopy and surface parameters (Liao et al., 2015; Xie et al., 2016). These overestimates are acceptable because the MB values are smaller than $1.8^{\circ}$ in January and smaller than $0.8^{\circ}$ in July. Moreover, when the gridded AH fluxes are taken into account (Grd_AH), the modeling results of air temperature can be improved, with the mean bias (MB) decreasing by $0.1-0.3^{\circ}$ and the correlation coefficient (COR) increasing by $0.02-0.05$ (from Fix_AH to Grd_AH). With regard to $\mathrm{RH}_{2}$, the modeling values from two simula- tions (Fix_AH and Grd_AH) are close to the observations. The best simulation occurs in Haikou, and the results at the other three sites are reasonable as well, with a bias within $\pm 10 \%$. These $2 \mathrm{~m}$ relative humidity predictions can be improved from Fix_AH to Grd_AH. When we consider the heterogeneity of AH fluxes in Grd_AH, the values of MB and RMSE are closer to 0 and those of COR are closer to 1 . For $\mathrm{WS}_{10}$, because the modeling near-surface wind speed is generally influenced by local underlying surface characteristics more than other meteorological parameters (Liao et al., 2015; Xie et al., 2016), both Fix_AH and Grd_AH slightly overvalue the $10 \mathrm{~m}$ wind speed at the four sites. In the case of Fix_AH, the MB for $\mathrm{WS}_{10}$ is generally around $1 \mathrm{~m} \mathrm{~s}^{-1}$ in both months, and the RMSE is less than $2.6 \mathrm{~m} \mathrm{~s}^{-1}$ in January and around $2 \mathrm{~m} \mathrm{~s}^{-1}$ in July. However, the predictions are obviously improved in the case of Grd_AH. The MB decreases to $0.4-0.9 \mathrm{~m} \mathrm{~s}^{-1}$ in January and $0.4-0.7 \mathrm{~m} \mathrm{~s}^{-1}$ in July, and the values of COR also increase from 0.68 (Fix_AH) to 0.74 (Grd_AH) in July. These improvements from Fix_AH to Grd_AH for $T_{2}, \mathrm{RH}_{2}$ and $\mathrm{WS}_{10}$ predictions suggest that the default value of WRF/Chem for all urban grids overestimates the AH fluxes in these cities, and our gridded $\mathrm{AH}$ data as well as the new parameterization scheme can exactly catch the heterogeneity of the heat released from the metropolitan areas of South China.

Table 5 also illustrates the performance of WRF/Chem simulations for the main air pollutants $\left(\mathrm{O}_{3}\right.$ and $\left.\mathrm{PM}_{10}\right)$. Obviously, both Fix_AH and Grd_AH can capture the magnitude and temporal variation of main air pollutants in these typical cities in South China, and the simulation with gridded AH fluxes (Grd_AH) can provide better predictions. For Grd_AH, the correlation coefficients (COR) for $\mathrm{PM}_{10}$ in all cities are around 0.62 in January and around 0.65 in July (statistically significant at the $95 \%$ confident level). The MB values for $\mathrm{PM}_{10}$ are only $-0.4-1.0 \mu \mathrm{g} \mathrm{m}^{-3}$ in January and $1.8-3.1 \mu \mathrm{g} \mathrm{m}^{-3}$ in July. With respect to $\mathrm{O}_{3}$, the values of $\mathrm{MB}$ are -9.2 to $-16.1 \mathrm{ppb}$ in January and -10.0 to $-13.5 \mathrm{ppb}$ in July. These underestimates can be related to the increasing of $\mathrm{WS}_{10}$ and the rising of the PBL caused by positive biases in $T_{2}$. The uncertainties in emissions of ozone precursors ( $\mathrm{NO}_{x}$ and VOCs) may cause these biases as well (Liao et al., 2015; Xie et al., 2016). However, the values of COR for $\mathrm{O}_{3}$ are $0.60-0.71$ in January and $0.60-0.64$ in July (statistically significant at the $95 \%$ confident level), proving that these modeling results are reasonable and acceptable.

Figure 3 presents the monthly-averaged differences of $\mathrm{O}_{3}$ and $\mathrm{PM}_{10}$ between Fix_AH and Grd_AH (Fix_AH minus Grd_AH) at the surface layer over the modeling domain 2 (D02). Obviously, there are some differences between the two simulations that use different AH parameterizations. These differences are more obvious in and around big cities because the AH is related to human activities. Moreover, the differences in January are higher than those in July, implying that the addition of $\mathrm{AH}$ can cause more atmospheric disturbances in winter. From this point of view, Grd_AH can 
Table 4. Annual average anthropogenic heat flux in different administrative districts in South China $\left(\mathrm{W} \mathrm{m}^{-2}\right)$.

\begin{tabular}{llrrrrrr}
\hline \multirow{2}{*}{ Province } & \multicolumn{7}{c}{ This study } \\
\cline { 3 - 7 } & & 1990 & 1995 & 2000 & 2005 & 2010 & 2014 \\
\hline \multirow{2}{*}{ Guangdong } & Regional $^{*}$ & 0.30 & 0.48 & 0.61 & 1.05 & 1.53 & 1.68 \\
& Urban area in PRD $_{\text {Guangxi }}$ & 5.11 & 11.13 & 14.51 & 30.82 & 49.41 & 58.03 \\
Hainan & Regional* & 0.11 & 0.16 & 0.17 & 0.26 & 0.38 & 0.44 \\
& Regional* & 0.04 & 0.09 & 0.14 & 0.23 & 0.37 & 0.49 \\
\hline
\end{tabular}

* Regional represents the average value over the whole area of a province.

better describe the spatial and temporal heterogeneity of the impacts of $\mathrm{AH}$ on regional air quality.

Above all, the WRF/Chem simulation accounting for the temporal and spatial distribution of AH (Grd_AH) has a relatively good capability in simulating urban climate and air quality over South China. So, the differences between the modeling results from Non_AH and Grd_AH can be used to quantify the impacts of anthropogenic heat on meteorology and air pollution.

\subsection{Impacts of AH on meteorological conditions}

Figures $4 \mathrm{a}-\mathrm{d}, 5 \mathrm{a}-\mathrm{d}$, and $6 \mathrm{a}-\mathrm{b}$ and $\mathrm{g}-\mathrm{h}$ show the impacts of AH on surface meteorology, which are defined as the monthly-averaged differences of these meteorological factors between Grd_AH and Non_AH (Grd_AH minus Non_AH) at the surface layer over the modeling domain 2. Figures $4 \mathrm{e}-\mathrm{f}$ and $6 \mathrm{c}-\mathrm{f}$ show the relevant vertical changes in the meteorological factors along the cross section from $\left(19.1^{\circ} \mathrm{N}, 108.9^{\circ} \mathrm{E}\right)$ to $\left(24.8^{\circ} \mathrm{N}, 114.7^{\circ} \mathrm{E}\right)$, which is shown as the solid line $A B$ in Fig. 1b. The vertical cross section analysis along this line discusses the different effects of $\mathrm{AH}$ on the ambient environment between a big (Guangzhou) and a relatively small (Haikou) city.

\subsubsection{Changes in surface energy and air temperature}

On account of $\mathrm{AH}$ and its diurnal variation being added to the sensible heat item in WRF/Chem, the addition of gridded AH fluxes should increase the modeling results of sensible heat fluxes (SHF) over South China. As shown in Fig. 4a and b, the spatial patterns of SHF changes in both January and July are similar to the spatial distribution of $\mathrm{AH}$ fluxes presented in Fig. 2f. The significant increments $\left(>10 \mathrm{~W} \mathrm{~m}^{-2}\right)$ of SHF over South China usually occur in and around megacities. In the PRD city cluster, in particular, adding AH can cause SHF to increase by over $50 \mathrm{~W} \mathrm{~m}^{-2}$ in both January and July.

For the $2 \mathrm{~m}$ air temperature $\left(T_{2}\right)$ over South China, the AH fluxes can increase their values by adding more surface heat to the atmosphere. As presented in Fig. $4 \mathrm{c}$ and d, the patterns of the monthly-averaged $T_{2}$ changes are similar to those of SHF (Fig. 4a and b). In the urban areas, the addition of AH can lead to a significant increase in $T_{2}$, which may enhance the urban heat islands (UHIs). For example, the UHI intensity (the difference of monthly mean temperature between the maximum in urban areas and the minimum in surrounding rural areas) in PRD is about $1.7^{\circ}$ in January and $1.3^{\circ}$ in July for the Non_AH case, while it increases to $2.4^{\circ}$ in January and $1.8^{\circ}$ in July for the Grd_AH case. The maximum $T_{2}$ changes are usually found in the city centers of the PRD region, with typical increments of over $1.1^{\circ}$ in January and of over $0.5^{\circ}$ in July. These findings are comparable to the values estimated for other cities (Fan and Sailor, 2005; Ferguson and Woodbury, 2007; Chen et al., 2009; Zhu et al., 2010; Menberg et al., 2013; Wu and Yang, 2013; Bohnenstengel et al., 2014; Yu et al., 2014; Xie et al., 2016) and can be confirmed by similar research in South China (Meng et al., 2011; Feng et al., 2012, 2014).

Figure $4 \mathrm{e}$ and $\mathrm{f}$ present the vertical changes in air temperature from the surface to the $800 \mathrm{hPa}$ layer along the line $\mathrm{AB}$ (shown in Fig. 1b), and illustrate that the increases in air temperature caused by adding $\mathrm{AH}$ are mainly confined to near the surface around the cities (Guangzhou and Haikou). These changes in air temperature in Guangzhou are more obvious than those in Haikou because the $\mathrm{AH}$ emissions are much higher in Guangzhou. Furthermore, $T_{2}$ changes in winter (Fig. 4e) are more obvious than those in summer (Fig. 4f), with the monthly mean increment of $T$ over $0.7^{\circ}$ for January but only around $0.4^{\circ}$ for July in Guangzhou. This phenomenon can be related to the fact that the background heat fluxes are much lower in winter so that the relative increase in $T$ is more obvious.

\subsubsection{Changes in boundary layer and wind field}

The warming up of surface air temperature can enhance the vertical air movement in the PBL and thereby can increase the height of the planetary boundary layer (PBLH) as well. As shown in Fig. 5a and b, the boundary layer height becomes higher when the $\mathrm{AH}$ fluxes are taken into account. The big increments (more than $50 \mathrm{~m}$ ) usually occur in the urban areas of the PRD region. Because a relatively higher temperature increment in January can induce a higher PBL in this cold season, the maximum changing values of PBLH can be $120 \mathrm{~m}$ for January but only $90 \mathrm{~m}$ for July. 


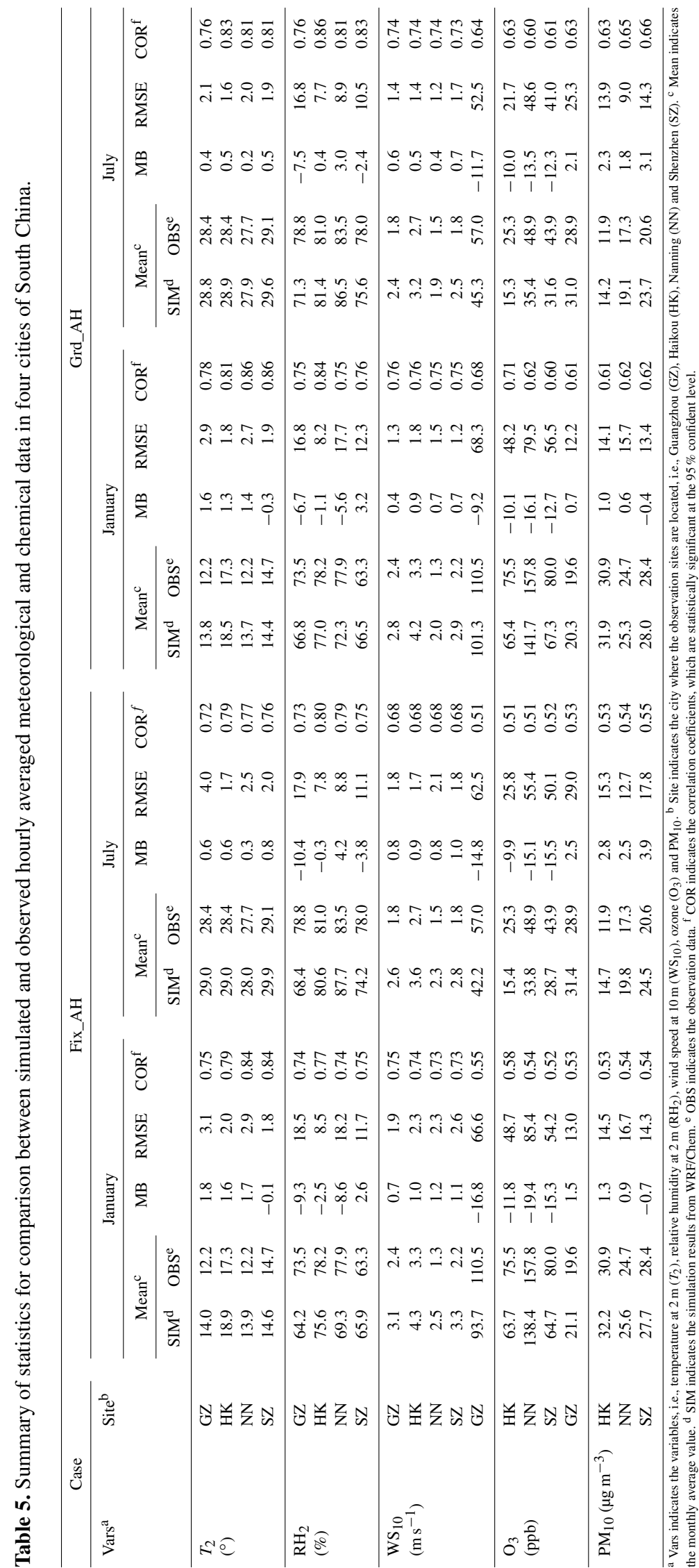



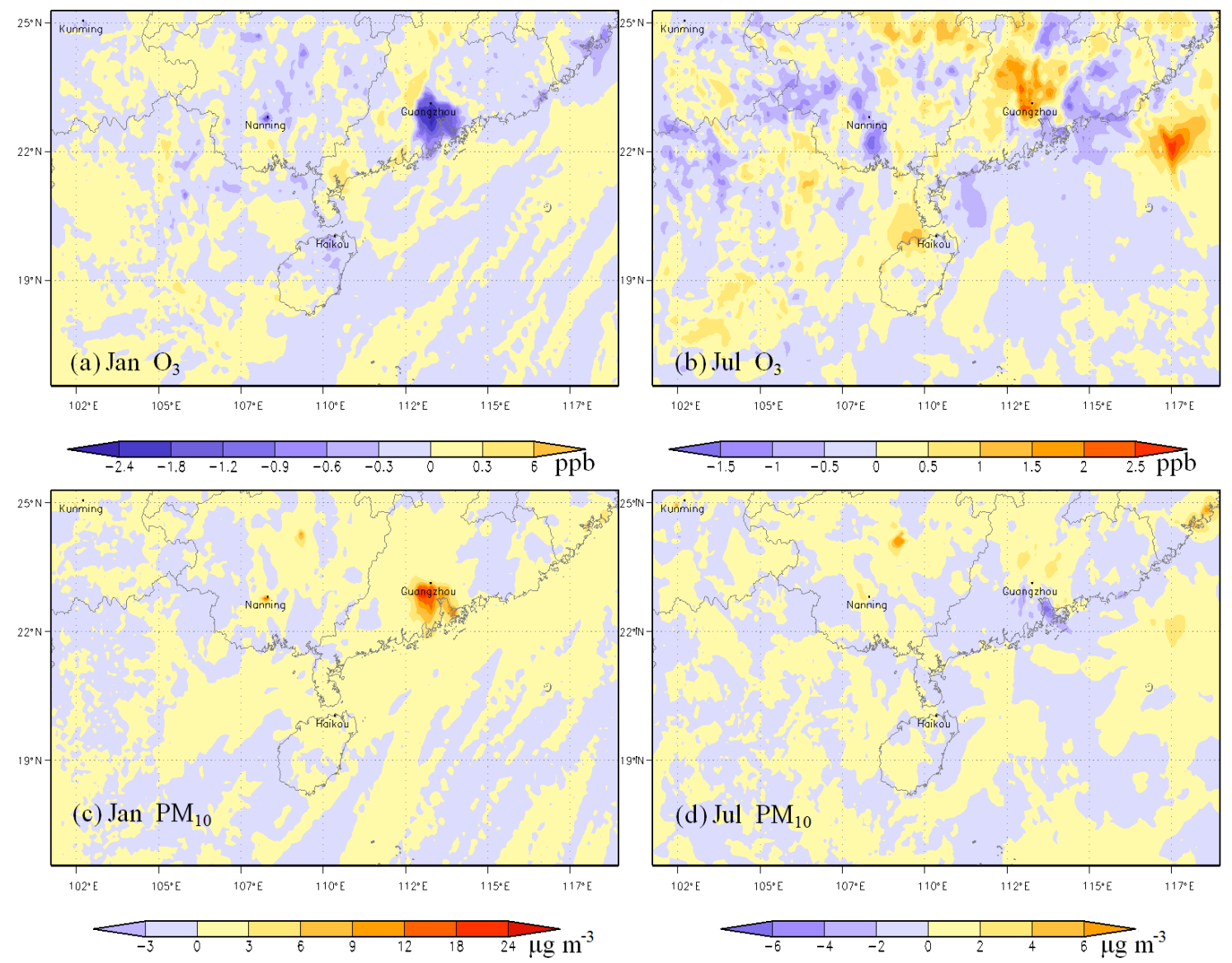

Figure 3. The spatial distributions of monthly-averaged differences for surface $\mathrm{O}_{3}$ and $\mathrm{PM}_{10}$ between Fix_AH and Grd_AH (Fix_AH - Grd_AH). Panels (a) and (c) show changes in January. Panels (b) and (d) illustrate variations in July.

Figure $5 \mathrm{c}$ and $\mathrm{d}$ show the changes in the $10 \mathrm{~m}$ wind speed over South China. Obviously, adding AH can enhance the surface wind in the urban areas. The maximum increase is located in the PRD region, with values of over $0.35 \mathrm{~m} \mathrm{~s}^{-1}$ in January and $0.3 \mathrm{~m} \mathrm{~s}^{-1}$ in July. In other cities like Chaozhou, Nanning and Haikou, the increments are merely about $0.1 \mathrm{~m} \mathrm{~s}^{-1}$. The warming of air temperature near the surface as well as the rising of PBLH induced by adding AH in cities can generate an enhanced urban-breeze circulation. In previous studies, the increases in surface wind speed were considered to be related to this strengthened urbanbreeze circulation (Chen et al., 2009; Ryu et al., 2013; Yu et al., 2014; Xie et al., 2016). Our results show that the vertical wind velocities above Guangzhou and Haikou are enhanced in both January and July (Fig. 6c and d), and the simulated convergence at the surface near these cities increases by $0.04-0.13 \mathrm{~s}^{-1}$ in January and $0.05-0.18 \mathrm{~s}^{-1}$ in July (not shown). Consequently, we deduce that the enhanced vertical air movement causes stronger surface convergence and thereby induces higher surface wind speed. It is worth mentioning that the changes in vertical air movement and surface wind may affect the local land-sea breeze circulation in coastal cities. For example, AH emission in Haikou enhances the upward air movement above the city (Fig. $6 \mathrm{c}$ and d), causes the downward movement above the surrounding waters (Fig. $6 \mathrm{c}$ and d) and increases the surface wind from sea to land (stronger convergence). These changes imply that AH might strengthen sea breeze in the daytime and weaken land breeze at night.

\subsubsection{Changes in moisture and rainfall}

Figure $6 \mathrm{a}$ and $\mathrm{b}$ present the monthly-averaged differences of water vapor mixing ratio (VAPOR) at $2 \mathrm{~m}$ between Grd_AH and Non_AH. Obviously, the air near the surface of cities becomes dryer. The negative centers occur in the PRD region, the Chao-Shan area and some other cities, such as Haikou and Nanning. These cities are also the AH emission centers seen in Fig. 2f. In the urban areas of PRD, the reductions in surface VAPOR can be -0.1 to $-0.3 \mathrm{~g} \mathrm{~kg}^{-1}$ in January and -0.2 to $-0.5 \mathrm{~g} \mathrm{~kg}^{-1}$ in July.

It was reported that the enhanced vertical air movement can transport more moisture from the surface to the upper layer and thereby can modify the spatial and vertical dis- 
(a) Horizontal changes in SHF in Jan $\left(\mathrm{W} \mathrm{m}^{-2}\right)$

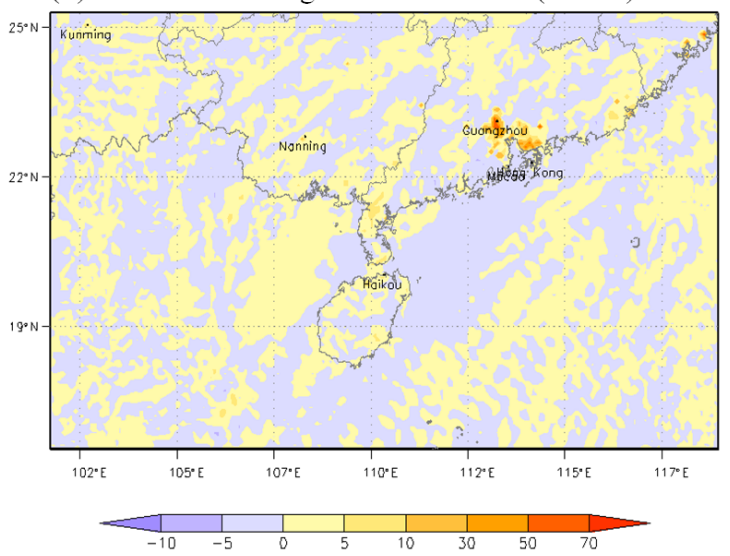

(c) Horizontal changes in $\mathrm{T}_{2}$ in $\operatorname{Jan}\left({ }^{\circ} \mathrm{C}\right)$
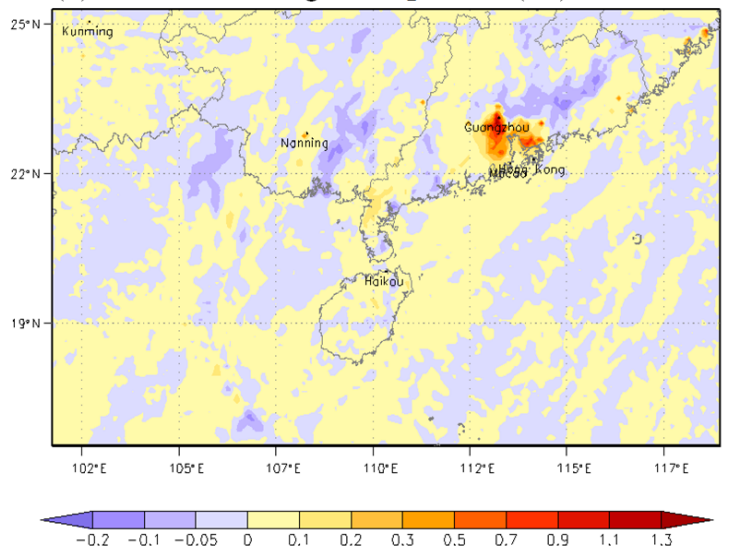

(e) Vertical changes in $\mathrm{T}$ in $\operatorname{Jan}\left({ }^{\circ} \mathrm{C}\right)$

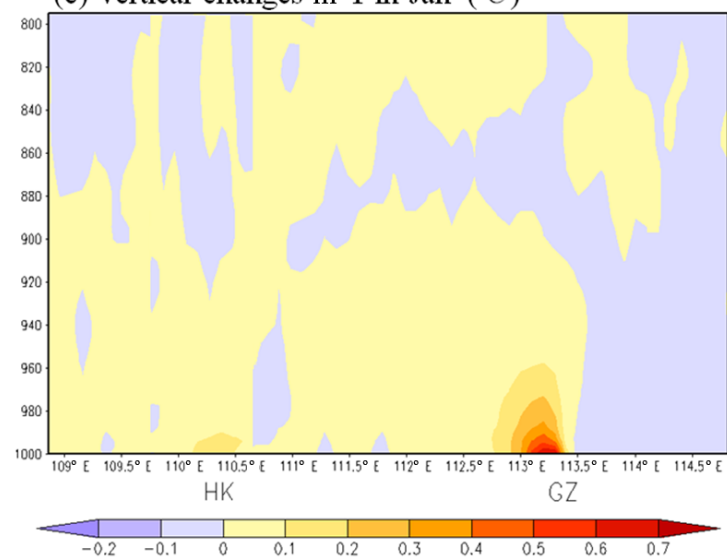

(b) Horizontal changes in SHF in Jul $\left(\mathrm{W} \mathrm{m}^{-2}\right)$

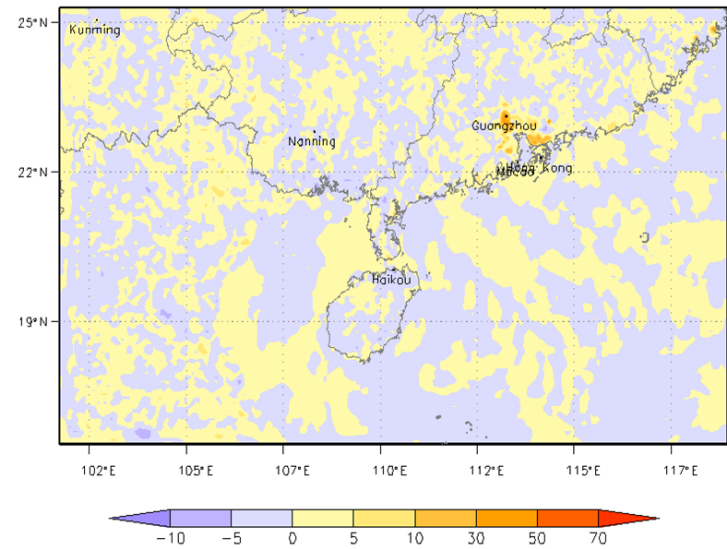

(d) Horizontal changes in $\mathrm{T}_{2}$ in Jul $\left({ }^{\circ} \mathrm{C}\right)$

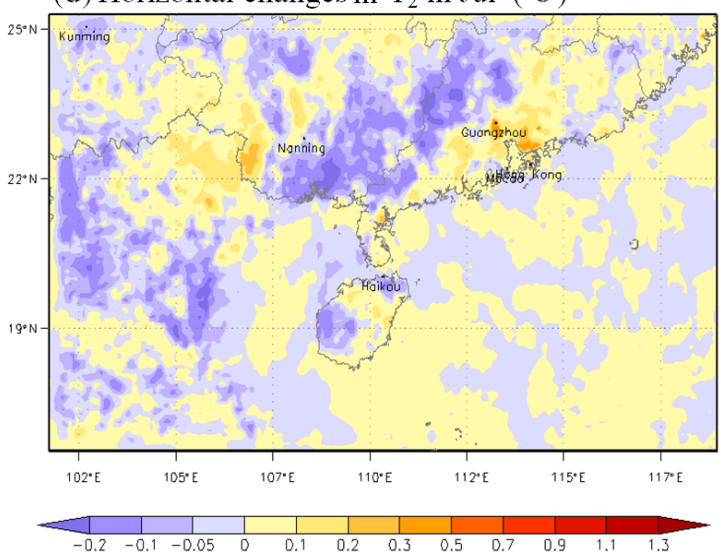

(f) Vertical changes in $\mathrm{T}$ in $\mathrm{Jul}\left({ }^{\circ} \mathrm{C}\right)$

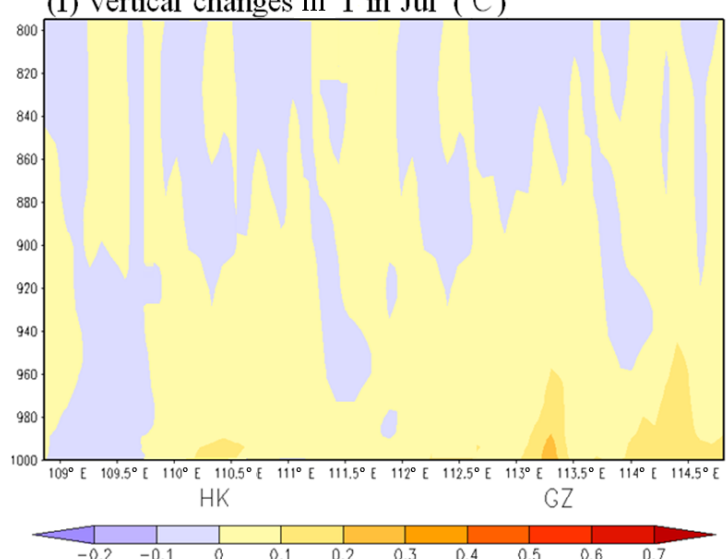

Figure 4. The monthly-averaged differences between Grd_AH and Non_AH (Grd_AH minus Non_AH) for (a) and (b), the spatial distribution of sensible heat flux (SHF); (c) and (d) show the spatial distribution of $2 \mathrm{~m}$ air temperature $\left(T_{2}\right)$; (e) and (f) show the vertical distribution of air temperature $(T)$ from the surface to the $800 \mathrm{hPa}$ layer along the line AB shown in Fig. 1b. Grd_AH and Non_AH represent the simulations with and without AH fluxes. Panels (a), (c) and (e) show changes in January, while (b), (d) and (f) illustrate variations in July. In (e) and (f), HK and GZ are the abbreviations for Haikou and Guangzhou, respectively.

tributions of moisture (Xie et al., 2016). This effect mechanism can be clearly illustrated by Fig. $6 \mathrm{c}-\mathrm{f}$ in this study. As shown in Fig. $6 \mathrm{c}$ and $\mathrm{d}$, the vertical wind velocities above Guangzhou and Haikou increase by the values of 0.2 $0.5 \mathrm{~cm} \mathrm{~s}^{-1}$ in January and $0.5-1.0 \mathrm{~cm} \mathrm{~s}^{-1}$ in July, whereas $w$ decreases in rural areas, with reductions of about $-0.3 \mathrm{~m} \mathrm{~s}^{-1}$ 
(a) Spatial changes in PBLH in Jan (m)

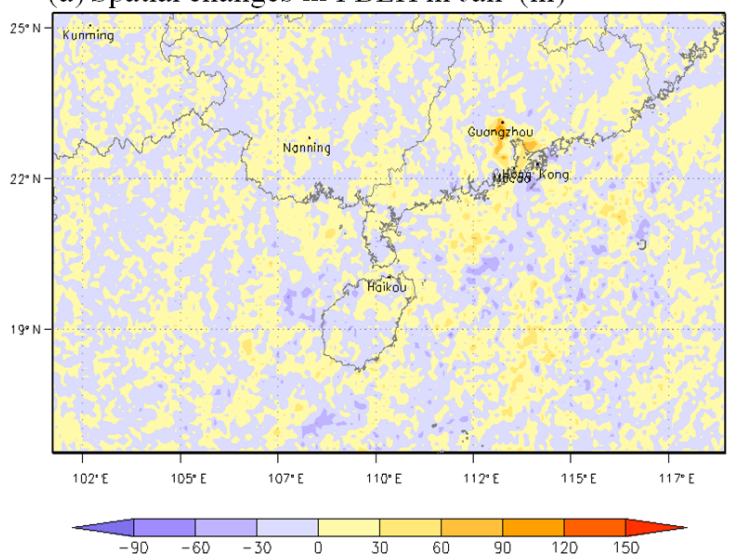

(c) Spatial changes in $\mathrm{WS}_{10}$ in Jan $\left(\mathrm{m} \mathrm{s}^{-1}\right)$

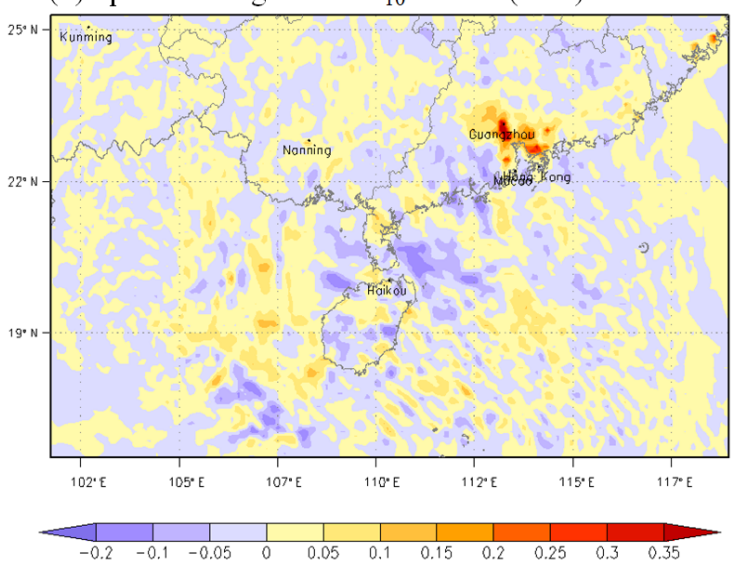

(b) Spatial changes in PBLH in Jul (m)

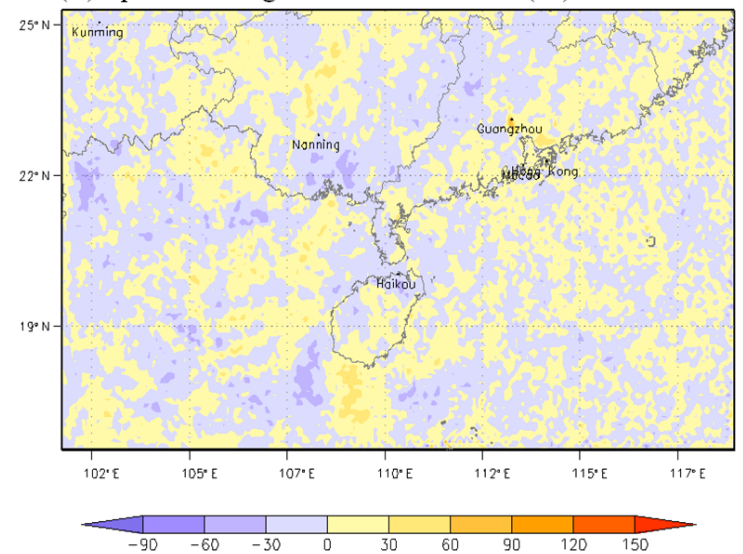

(d) Spatial changes in $\mathrm{WS}_{10}$ in Jul $\left(\mathrm{m} \mathrm{s}^{-1}\right)$

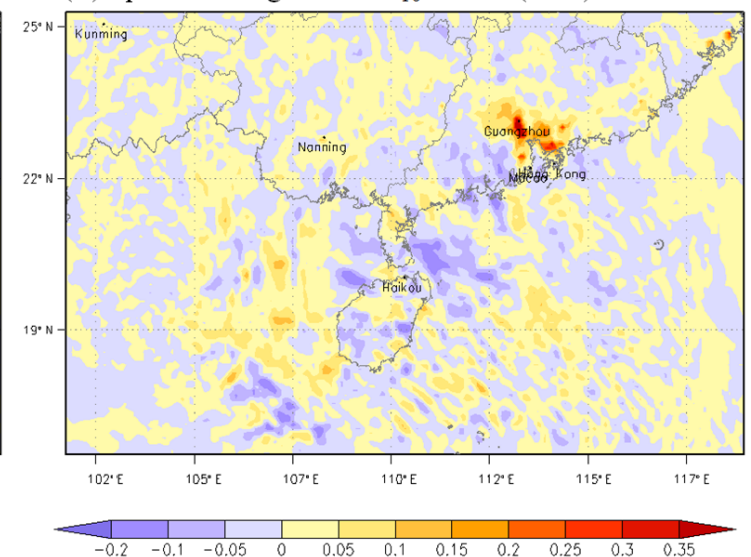

Figure 5. The monthly-averaged differences of the height of planetary boundary layer (PBLH) and $10 \mathrm{~m}$ wind speed (WS 10 ) between Grd_AH and Non_AH (Grd_AH minus Non_AH). Grd_AH and Non_AH represent the simulations with and without AH fluxes. Panels (a) and (c) show changes in January, while (b) and (d) illustrate variations in July.

in January and over $-0.5 \mathrm{~cm} \mathrm{~s}^{-1}$ in July. This pattern means that there is a strengthened upward air flow in cities and a strengthened downward air flow in the surrounding areas, implying that the addition of $\mathrm{AH}$ fluxes makes the atmosphere more unstable and tends to form deep convections in the troposphere. So, as shown in Fig. 6e and f, more moisture can be transported from the surface to the upper layers. In Guangzhou, for example, the water vapor mixing ratios at the ground level decrease by $-0.3 \mathrm{~g} \mathrm{~kg}^{-1}$ in January and $-0.5 \mathrm{~g} \mathrm{~kg}^{-1}$ in July, while those at the upper PBL increase by $0.1 \mathrm{~g} \mathrm{~kg}^{-1}$ in January and $0.3 \mathrm{~g} \mathrm{~kg}^{-1}$ in July. The impact of $\mathrm{AH}$ on water vapor is stronger in July. This seasonal difference can be ascribed to the fact that the atmosphere is more stagnant and dryer in winter and more convective and wetter in summer. Furthermore, the changes in Haikou are generally smaller than those in Guangzhou, which can be explained by the fact that the AH emissions are much lower in Haikou.

More moisture transported from the surface into the midtroposphere can increase the precipitation in these urban areas as well. Figure $6 \mathrm{~g}$ and $\mathrm{h}$ illustrate the enhanced rainfall over South China both in January and July. Because of the negligible accumulative precipitation in winter, there are no significant differences between the Grd_AH and Non_AH simulations for rainfall in January. But in July the increment in rainfall can be more than $50 \mathrm{~mm}$ in and around big cities. Moreover, according to the dominant southeast wind in summer, the moisture can be transported to the downwind areas of the PRD city cluster, which causes the increases in rainfall in the northwest part of Guangdong province, with a maximum value of over $80 \mathrm{~mm}$.

\subsubsection{Diurnal pattern of the changes}

In order to better understand the different impacts of $\mathrm{AH}$ in the daytime and at night, the monthly-averaged diurnal variations of $T_{2}$, PBLH and $\mathrm{WS}_{10}$ in January and July over the urban areas in Guangzhou are calculated based on the results from Grd_AH and Non_AH. As shown in Fig. 7a and $\mathrm{b}$, adding AH fluxes can lead to an obvious increase in $2 \mathrm{~m}$ air temperature in both months, with a daily mean increase 
(a) Spatial changes in VAPOR in Jan $\left(\mathrm{g} \mathrm{kg}^{-1}\right)$

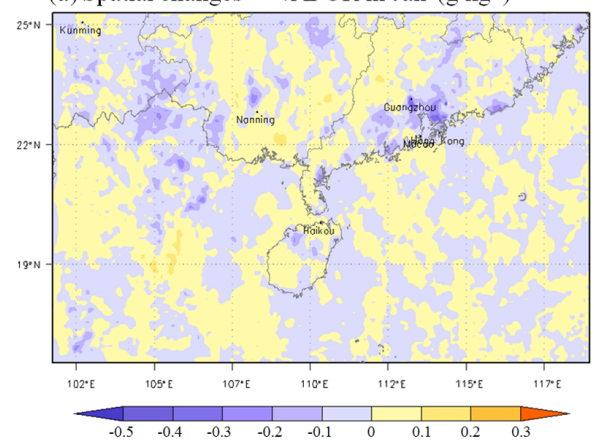

(c) Vertical changes in $\mathrm{w}$ in Jan $\left(\mathrm{cm} \mathrm{s}^{-1}\right)$

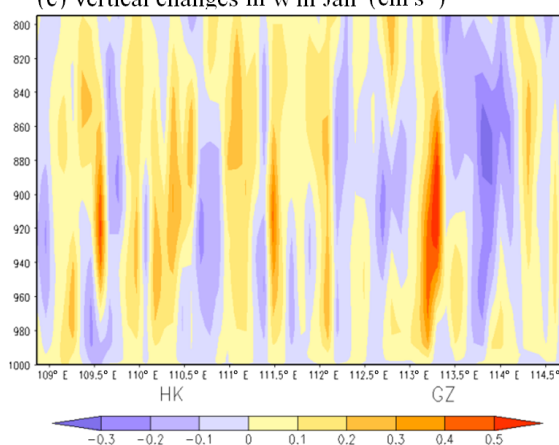

(e) Vertical changes in VAPOR in Jan $\left(\mathrm{g} \mathrm{kg}^{-1}\right)$

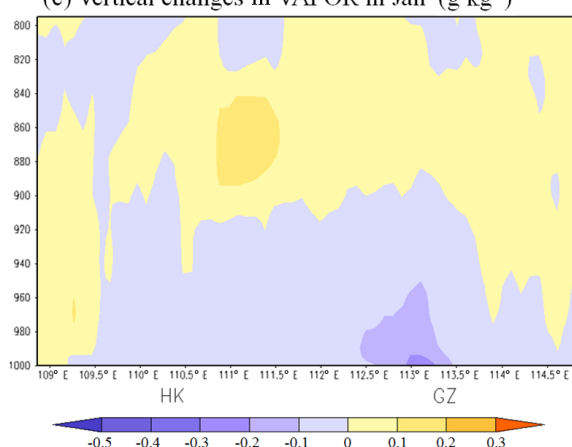

(g) Spatial changes in RAIN in Jan ( $\mathrm{mm})$

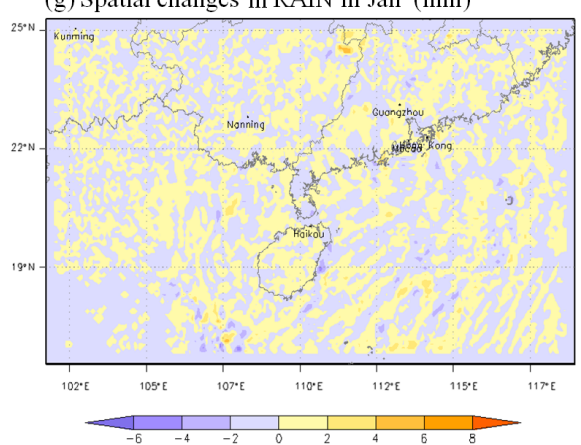

(b) Spatial changes in VAPOR in Jul $\left(\mathrm{g} \mathrm{kg}^{-1}\right)$

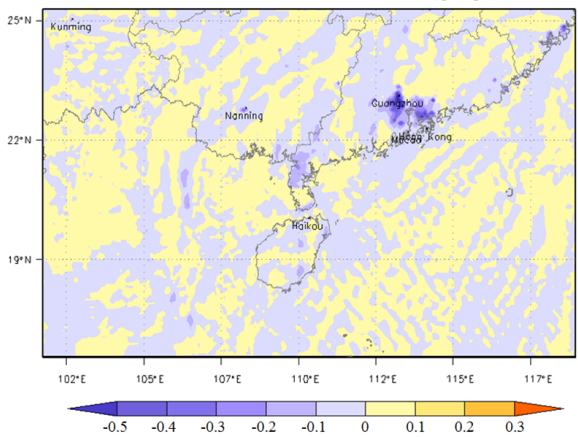

(d) Vertical changes in w in Jul $\left(\mathrm{cm} \mathrm{s}^{-1}\right)$

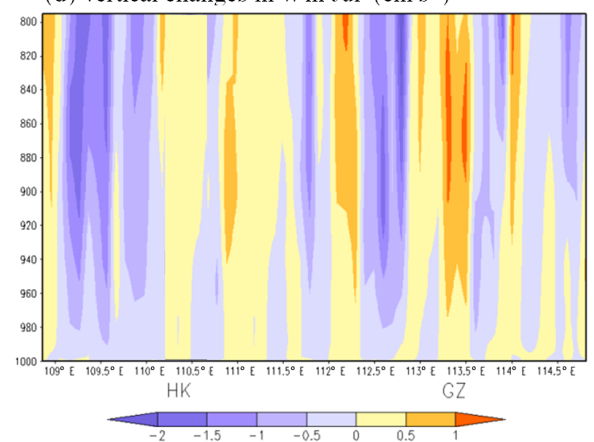

(f) Vertical changes in VAPOR in Jul $\left(\mathrm{g} \mathrm{kg}^{-1}\right)$

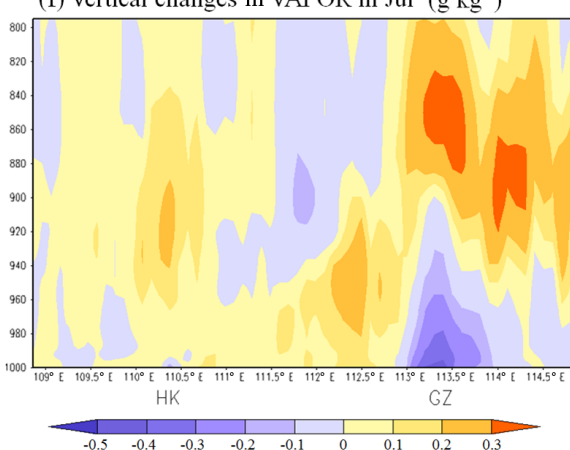

(h) Spatial changes in RAIN in Jul (mm)

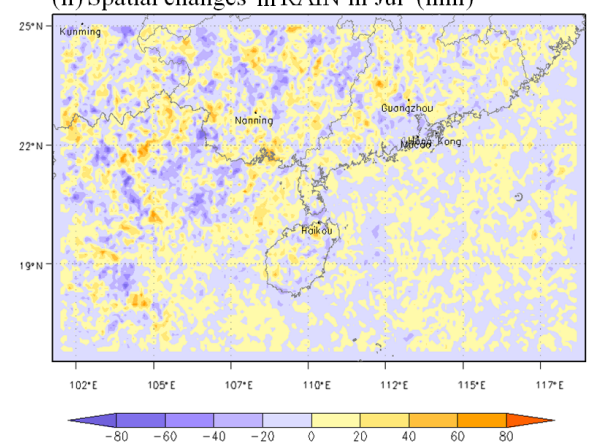

Figure 6. The monthly-averaged differences between Grd_AH and Non_AH (Grd_AH minus Non_AH) for (a) and (b), the spatial distribution of water vapor mixing ratio (VAPOR) at $2 \mathrm{~m}$; (c) and (d) show the vertical distribution of vertical wind velocity $(w)$; (e) and (f) show the vertical distribution of VAPOR; (g) and (h) show the spatial distribution of precipitation (RAIN). The vertical cross section is from the surface to the $800 \mathrm{hPa}$ layer along the line AB shown in Fig. 1b. Grd_AH and Non_AH represent the simulations with and without AH fluxes. Panels (a), (c), (e) and (g) show changes in January, while (b), (d), (f) and (g) illustrate variations in July. In (c), (d), (e) and (f), HK and GZ are the abbreviations for Haikou and Guangzhou, respectively. 

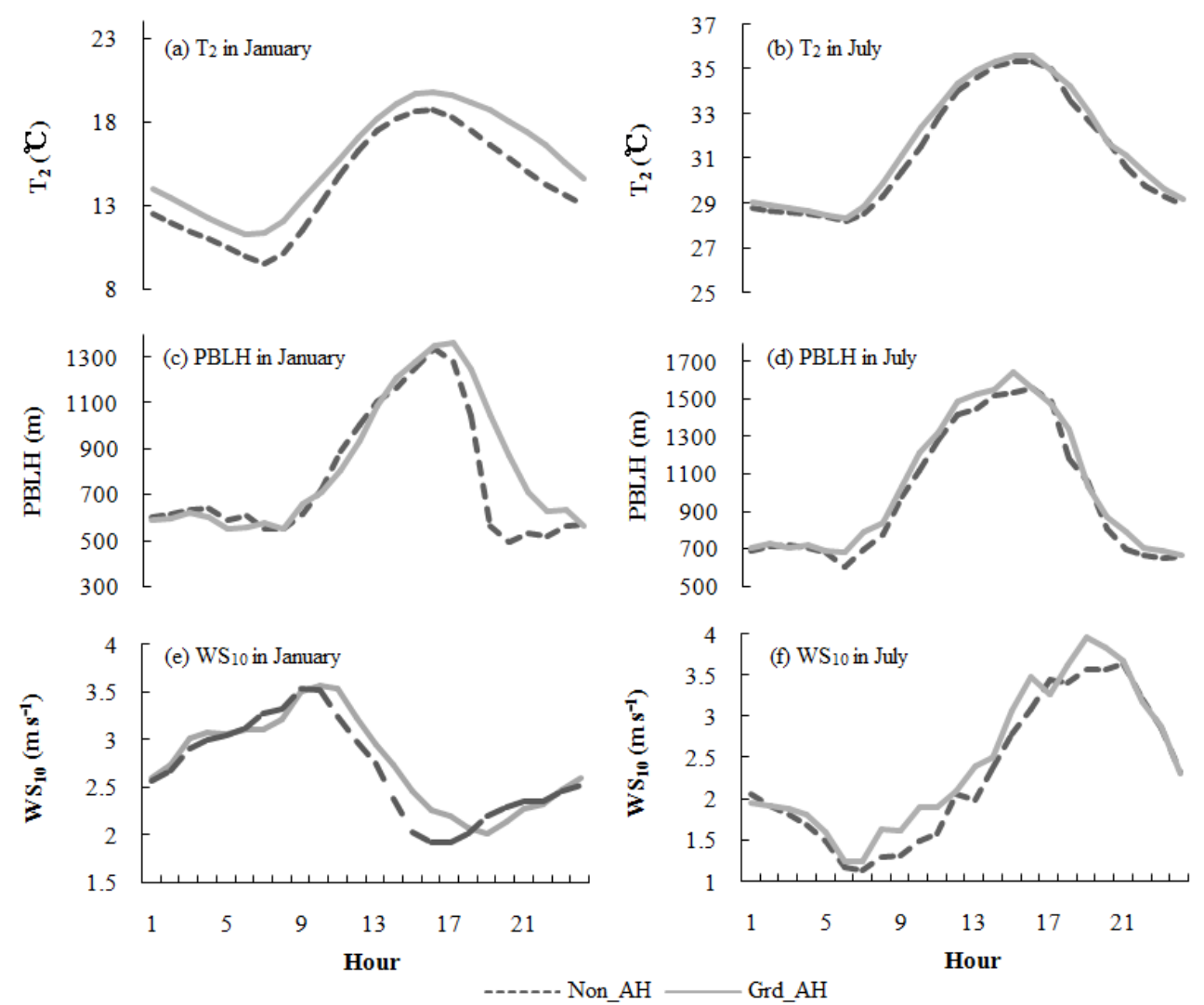

Figure 7. The monthly-averaged diurnal variations for $2 \mathrm{~m}$ air temperature $\left(T_{2}\right)$, the height of planetary boundary layer (PBLH) and $10 \mathrm{~m}$ wind speed $\left(\mathrm{WS}_{10}\right)$ over the urban areas in Guangzhou. Grd_AH and Non_AH represent the simulations with and without AH fluxes, respectively. Panels (a), (c) and (e) show diurnal curves in January, while (b), (d) and (f) illustrate those in July.

of $1.5^{\circ}$ for January and $0.6^{\circ}$ for July. The increment of $T_{2}$ at night in January $\left(1.69^{\circ}\right)$ is larger than that in the daytime $\left(1.31^{\circ}\right)$, whereas the changes during the whole day in July are all around $0.6^{\circ}$, which suggests that AH can weaken the diurnal $T_{2}$ variation in winter. With respect to PBLH, the AH fluxes can also result in a higher boundary layer. In July (Fig. 7d), the increment of PBLH remains at a nearly constant value of $54 \mathrm{~m}(4.7 \%)$ from morning till night. However, in January (Fig. 7c), the nighttime increase in PBLH is much higher than that in the daytime. This phenomenon may be related to the fact that the absolute PBLH values are lower and the air temperatures increase more in winter nights. For $\mathrm{WS}_{10}, \mathrm{AH}$ emission causes it to increase by $0.07 \mathrm{~m} \mathrm{~s}^{-1}$ in January and by $0.15 \mathrm{~m} \mathrm{~s}^{-1}$ in July. Most increases occur in the daytime. The effect of $\mathrm{AH}$ on surface wind is negligible at night, which may be related to the fact that the land breeze at night (from land to sea) hinders the surface convergence (from sea to land) caused by $\mathrm{AH}$.

\subsection{Impacts of AH on main air pollutants}

\subsubsection{Changes in the spatial and vertical distribution of $\mathbf{P M}_{10}$}

Since adding AH changes the atmospheric conditions, it can affect the transportation and dispersion of air pollutants as well. Figure 8a and $\mathrm{b}$ show the effects of $\mathrm{AH}$ on the spatial distribution of $\mathrm{PM}_{10}$ at the surface layer over South China in January and July. They illustrate that the concentrations of $\mathrm{PM}_{10}$ decrease in both season near the big cities, including the PRD city cluster, the Chao-Shan area and Nanning. The maximum reductions occur in the PRD region, with a monthly mean value of over $-10 \mu \mathrm{g} \mathrm{m}^{-3}$ for January and about $-5 \mu \mathrm{g} \mathrm{m}^{-3}$ for July. Compared with the distribution of $\mathrm{AH}$ emissions as well as their effects on meteorological conditions, the main causes resulting in the reduction in surface $\mathrm{PM}_{10}$ can be attributed to the increase in PBLH, vertical upward air flow and surface wind speed, which can all facilitate $\mathrm{PM}_{10}$ transport and dispersion within the urban boundary layer. With regard to another aspect, as shown in Fig. 6h, the rainfall around the PRD cities can increase by $20-40 \%$ in July when the AH fluxes are taken into account, so the 
(a) Spatial changes in $\mathrm{PM}_{10}$ in Jan $\left(\mu \mathrm{g} \mathrm{m}^{-3}\right)$

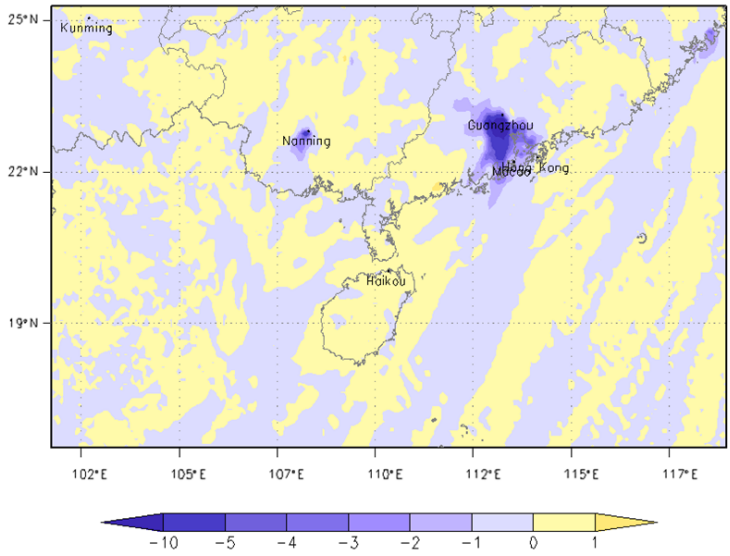

(c) Vertical changes in $\mathrm{PM}_{10}$ in $\operatorname{Jan}\left(\mu \mathrm{g} \mathrm{m}^{-3}\right)$

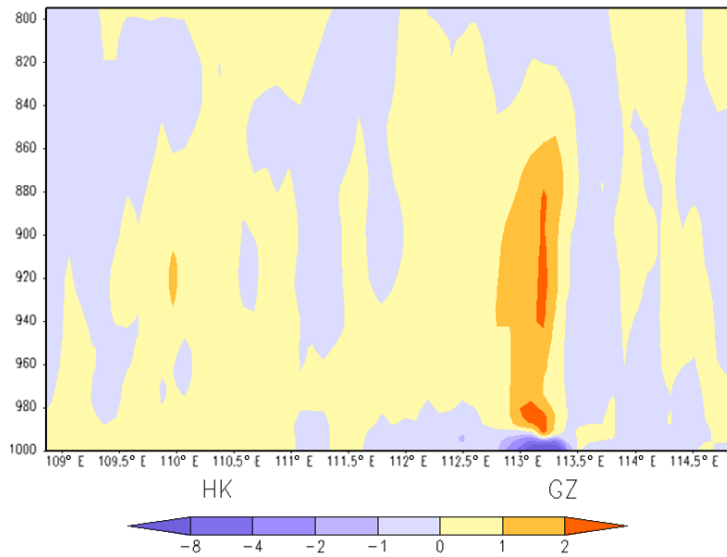

(e) Diurnal variation in $\mathrm{PM}_{10}$ in Jan

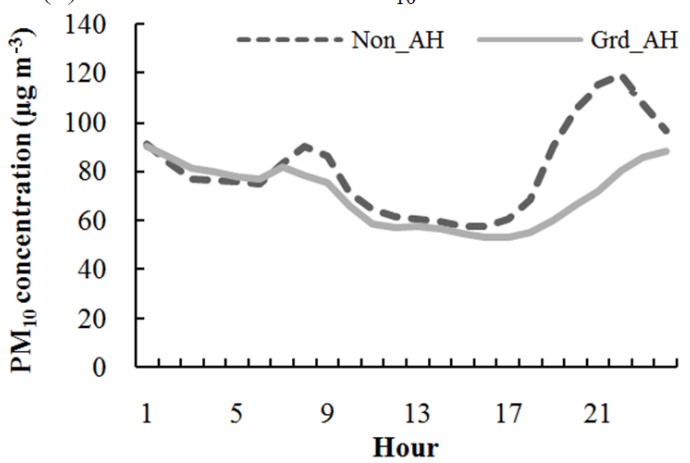

(b) Spatial changes in $\mathrm{PM}_{10}$ in Jul $\left(\mu \mathrm{g} \mathrm{m}^{-3}\right)$

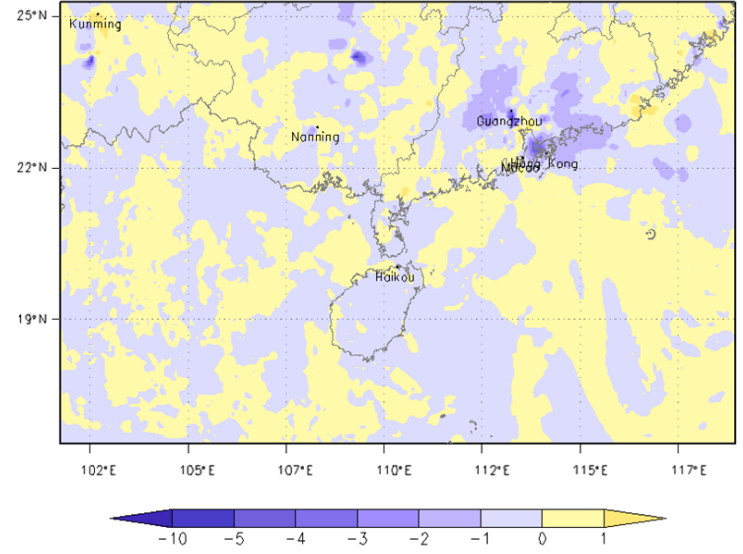

(d) Vertical changes in $\mathrm{PM}_{10}$ in $\mathrm{Jul}\left(\mu \mathrm{g} \mathrm{m} \mathrm{m}^{-3}\right)$

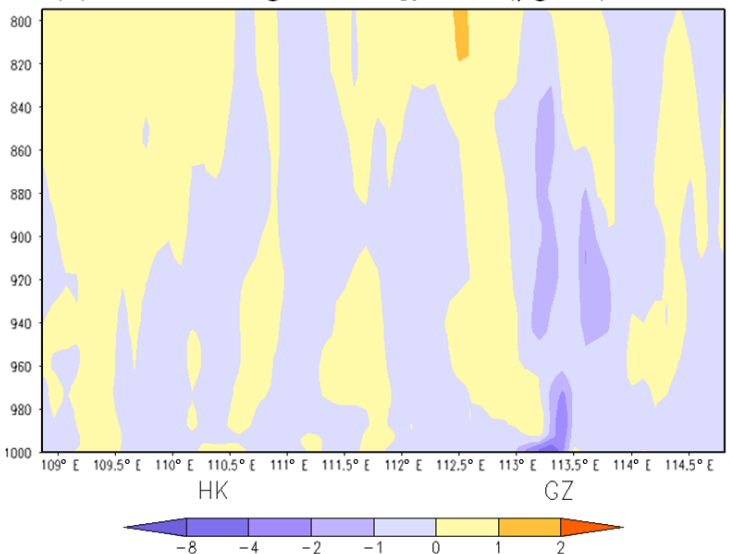

(f) Diurnal variation in $\mathrm{PM}_{10}$ in Jul

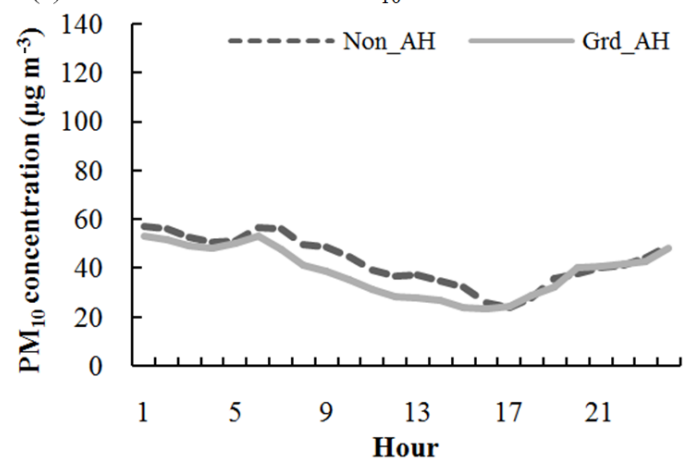

Figure 8. Impacts of $\mathrm{AH}$ fluxes on the concentrations of $\mathrm{PM}_{10}$ : (a) and (b) show the spatial distribution of monthly-averaged differences for PM 10 between Grd_AH and Non_AH (Grd_AH minus Non_AH) at the surface layer; (c) and (d) show the vertical distribution of monthlyaveraged differences for PM 10 between Grd_AH and Non_AH (Grd_AH minus Non_AH) from the surface to the $800 \mathrm{hPa}$ layer along the line AB shown in Fig. 1b; (e) and (f) show the monthly-averaged diurnal variations for $\mathrm{PM}_{10}$ concentrations over the urban areas in Guangzhou. Grd_AH and Non_AH represent the simulations with and without AH fluxes. Panels (a), (c) and (e) show changes in January, while (b), (d) and (f) illustrate variations in July. In (c) and (d), HK and GZ are the abbreviations for Haikou and Guangzhou, respectively.

strengthened wet scavenging in summer may contribute to the decreases in the surface concentrations of $\mathrm{PM}_{10}$ as well. The surface reductions in $\mathrm{PM}_{10}$ induced by adding $\mathrm{AH}$ in the PRD region are smaller than those reported by Xie et al. (2016) in the Yangtze River Delta (YRD) region, which may be attributed to the fact that the particle pollution is more severe and the $\mathrm{AH}$ emissions as well as their effects on meteorology are more obvious in the YRD region.

Figure $8 \mathrm{c}$ and $\mathrm{d}$ present the vertical plots for the changes in $\mathrm{PM}_{10}$ impacted by adding AH (Grd_AH minus Non_AH) 
(a) Spatial changes in $\mathrm{O}_{3}$ in Jan (ppb)

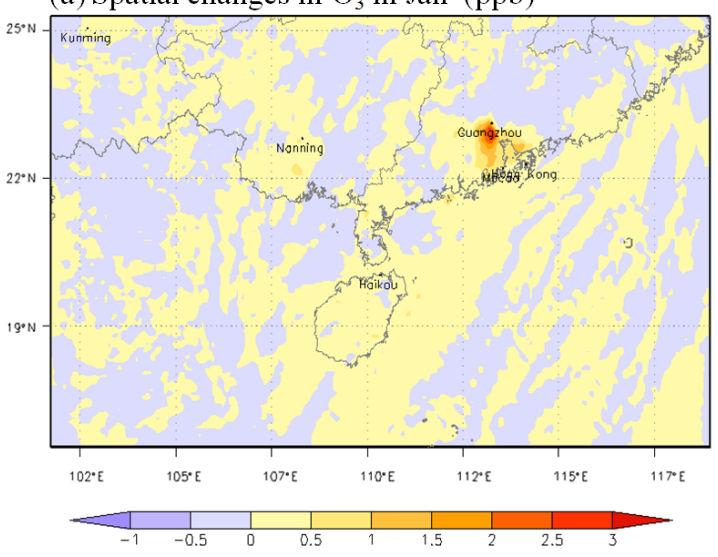

(c) Vertical changes in $\mathrm{O}_{3}$ in Jan $(\mathrm{ppb})$

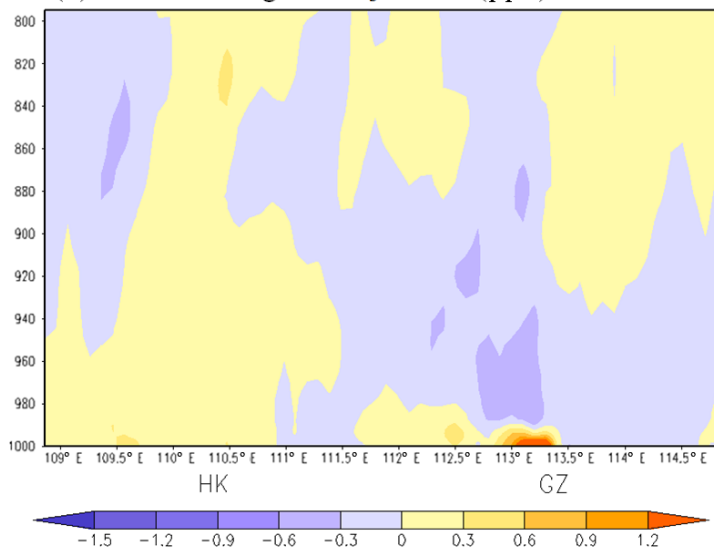

(b) Spatial changes in $\mathrm{O}_{3}$ in Jul (ppb)

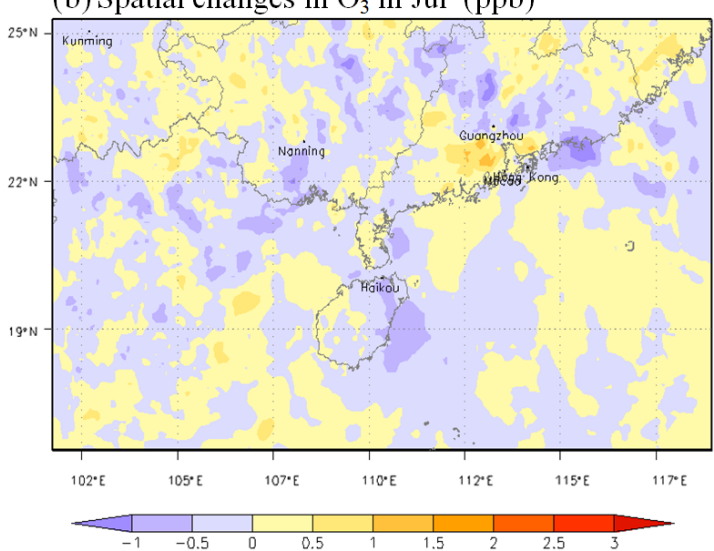

(d) Vertical changes in $\mathrm{O}_{3}$ in Jul (ppb)

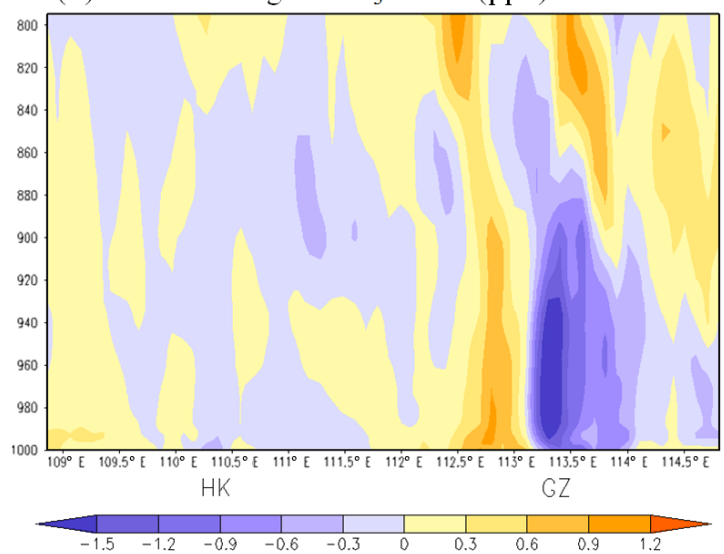

Figure 9. Impacts of $\mathrm{AH}$ fluxes on the concentrations of $\mathrm{O}_{3}$ : (a) and (b) show the spatial distribution of monthly-averaged differences for $\mathrm{O}_{3}$ between Grd_AH and Non_AH (Grd_AH minus Non_AH) at the surface layer; (c) and (d) show the vertical distribution of monthly-averaged differences for $\mathrm{O}_{3}$ between Grd_AH and Non_AH (Grd_AH minus Non_AH) from the surface to the 800hPa layer along the line AB shown in Fig. 1b. Grd_AH and Non_AH represent the simulations with and without AH fluxes. Panels (a) and (c) show changes in January, while (b) and (d) illustrate variations in July. In (c) and (d), HK and GZ are the abbreviations for Haikou and Guangzhou, respectively.

on the cross-sectional line $\mathrm{AB}$ shown in Fig. 1b. With respect to the megacity Guangzhou, the AH fluxes can decrease the concentrations of $\mathrm{PM}_{10}$ near the surface and increase those at the upper layers. This vertical change pattern of $\mathrm{PM}_{10}$ is quite similar to that of water vapor (Fig. 6e and f), indicating that it is a reflection of the changes in the vertical transport pattern due to AH (Yu et al., 2014; Xie et al., 2016). As shown in Fig. 8c for January, the decreases in $\mathrm{PM}_{10}$ mainly confined at the surface, with typical reductions over $-8 \mu \mathrm{g} \mathrm{m}^{-3}$. Meanwhile, there are obvious increases in $\mathrm{PM}_{10}$ concentrations at the upper levels, with increments of over $2 \mu \mathrm{g} \mathrm{m}^{-3}$ from the $980 \mathrm{hPa}$ layer to the $850 \mathrm{hPa}$ layer (approximately from 500 to $1500 \mathrm{~m}$ ). But for July (Fig. 8d), from the surface to the $850 \mathrm{hPa}$ layer over Guangzhou, the $\mathrm{PM}_{10}$ concentrations are all reduced by over $-1 \mu \mathrm{g} \mathrm{m}^{-3}$, with maximum values of over $-4 \mu \mathrm{g} \mathrm{m}^{-3}$ on the ground. The increasing zones only occur at the upper layers above $1.5 \mathrm{~km}$, with increments of over $1 \mu \mathrm{g} \mathrm{m}^{-3}$. This significant seasonal difference for the vertical distribution of $\mathrm{PM}_{10}$ changes over Guangzhou can be related to the fact that the atmosphere is more unstable and convective in summer than in winter, which can be further proven by the phenomenon of stronger enhanced upward air movement in July than that in January (shown in Fig. 6e and f). It should be noted that the vertical changes in $\mathrm{PM}_{10}$ in Haikou are indistinctive, implying that the surface air pollutants cannot be remarkably affected by adding $\mathrm{AH}$ if the heat emission fluxes are less than $10 \mathrm{~W} \mathrm{~m}^{-2}$. Furthermore, the low particle pollution level may be another cause of the negligible vertical changes in $\mathrm{PM}_{10}$ in Haikou.

Figure $8 \mathrm{e}$ and $\mathrm{f}$ show the monthly-averaged diurnal variations of surface PM 10 from the Grd_AH and Non_AH simulations over the urban areas in Guangzhou. Obviously, the addition of AH fluxes can lead to a decrease in surface $\mathrm{PM}_{10}$ concentrations, with a daily mean value of $-10.4 \mu \mathrm{g} \mathrm{m}^{-3}$ for January and $-4.3 \mu \mathrm{g} \mathrm{m}^{-3}$ for July. There are significant differences between the impacts of AH in the daytime and those at night. In July (Fig. 8f), the decreases mainly occur from 06:00 to 17:00 LT. In January (Fig. 8e), the decreases are 
(a) Spatial changes in $\mathrm{NO}_{\mathrm{x}}$ in Jan (ppb)

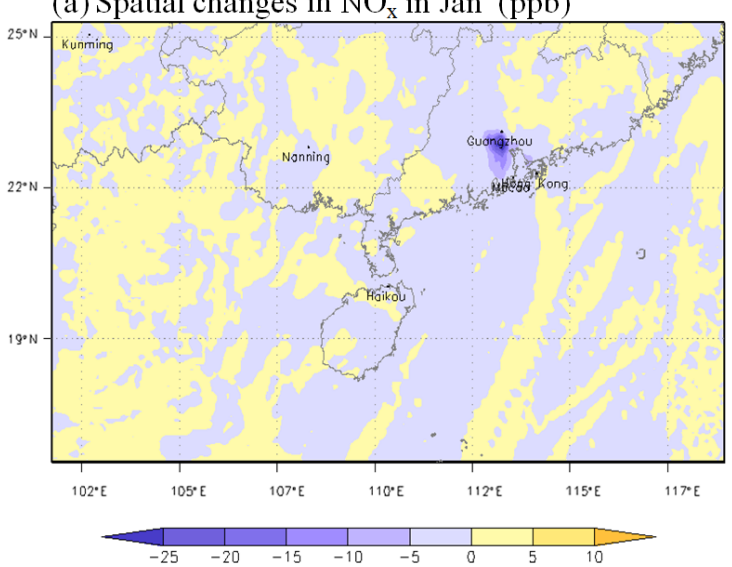

(c) Vertical changes in $\mathrm{NO}_{\mathrm{x}}$ in $\operatorname{Jan}(\mathrm{ppb})$

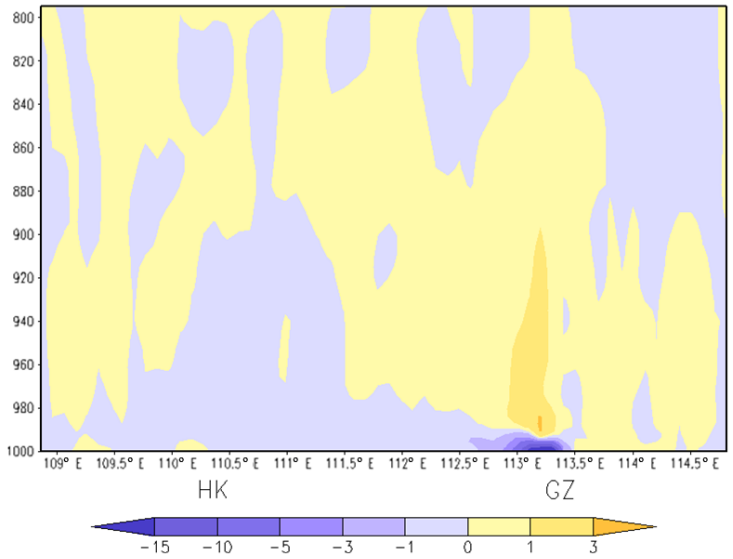

(b) Spatial changes in $\mathrm{NO}_{\mathrm{x}}$ in Jul (ppb)

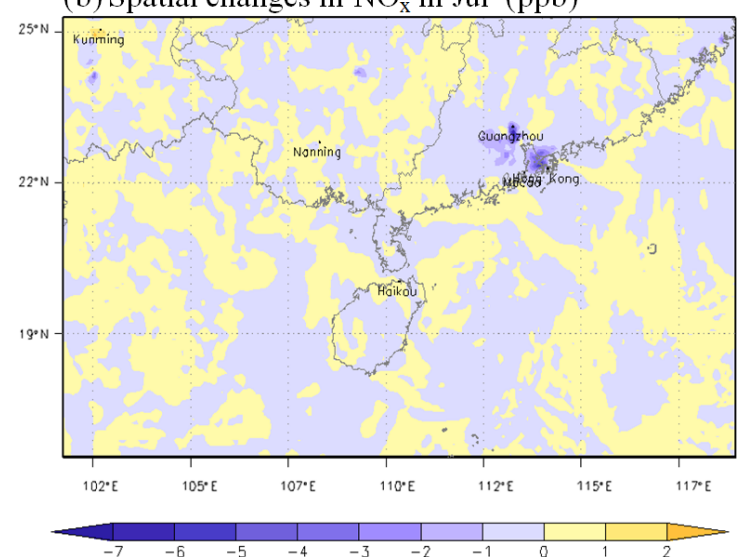

(d) Vertical changes in $\mathrm{NO}_{\mathrm{x}}$ in Jul (ppb)

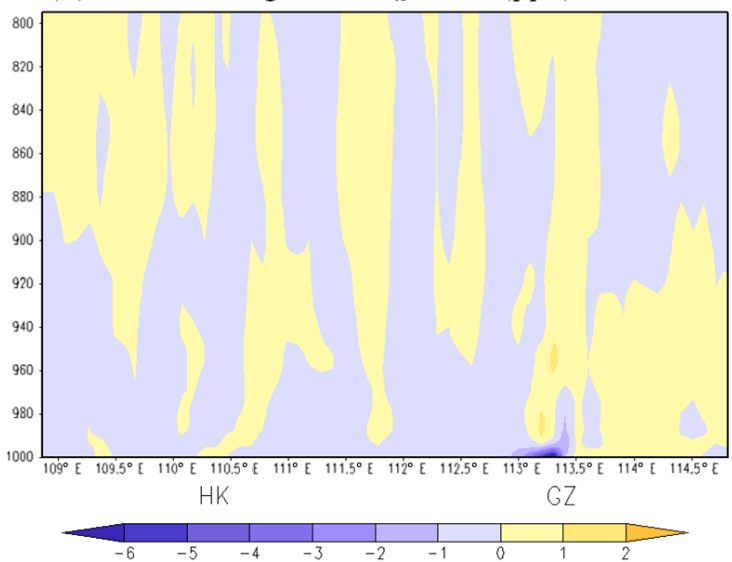

Figure 10. Impacts of $\mathrm{AH}$ fluxes on the concentrations of $\mathrm{NO}_{x}$ : (a) and (b) show the spatial distribution of monthly-averaged differences for $\mathrm{NO}_{x}$ between Grd_AH and Non_AH (Grd_AH minus Non_AH) at the surface layer; (c) and (d) show the vertical distribution of monthlyaveraged differences for $\mathrm{NO}_{x}$ between Grd_AH and Non_AH (Grd_AH minus Non_AH) from surface to $800 \mathrm{hPa}$ layer along the line AB shown in Fig. 1b. Grd_AH and Non_AH represent the simulations with and without AH fluxes. Panels (a) and (c) show changes in January, while (b) and (d) illustrate variations in July. In (c) and (d), HK and GZ are the abbreviations for Haikou and Guangzhou, respectively.

$-8.8 \mu \mathrm{g} \mathrm{m}^{-3}$ from 08:00 to $18: 00$ and $-11.9 \mu \mathrm{g} \mathrm{m}^{-3}$ from 19:00 to 07:00, with a maximum reduction of $-36.9 \mu \mathrm{g} \mathrm{\textrm {m } ^ { - 3 }}$ at 21:00. This pattern has a reverse correlation with the changes in PBLH shown in Fig. $7 \mathrm{c}$ and d, which also illustrates the important role of vertical air movement in the changes in $\mathrm{PM}_{10}$.

\subsubsection{Changes in the spatial and vertical distribution of $\mathrm{O}_{3}$}

Figure $9 \mathrm{a}$ and $\mathrm{b}$ present the effects of $\mathrm{AH}$ on the spatial distribution of $\mathrm{O}_{3}$ at the surface layer over South China. The results show that the increases in surface $\mathrm{O}_{3}$ level can be seen in megacities for both January and July. In January (Fig. 9a), the maximum $\mathrm{O}_{3}$ differences occur in the big cities of the PRD region, with the monthly mean increment over $2.5 \mathrm{ppb}$. In July (Fig. 9b), the increasing areas become larger, but with high values close to $1 \mathrm{ppb}$ in and around the cities. This changing pattern is similar to the findings reported in Seoul
(Ryu et al., 2013), Beijing (Yu et al., 2014) and the cities in the YRD region (Xie et al., 2016).

Figure $9 \mathrm{c}$ and $\mathrm{d}$ show the effects of $\mathrm{AH}$ on the vertical distribution of $\mathrm{O}_{3}$ from the surface to the $800 \mathrm{hPa}$ layer along the line $A B$ (illustrated in Fig. 1b). For the urban areas of Haikou, the vertical changes in $\mathrm{O}_{3}$ are all within $\pm 0.2 \mathrm{ppb}$, which means that low AH emissions in this city $\left(<10 \mathrm{~W} \mathrm{~m}^{-2}\right)$ cannot remarkably affected the physical and chemical formation of $\mathrm{O}_{3}$. However, over the urban areas of the big city Guangzhou, the vertical distribution of $\mathrm{O}_{3}$ concentrations can be noticeably changed. In January (Fig. 9c), $\mathrm{O}_{3}$ increases at the surface, while it decreases at the upper levels. The increases in $\mathrm{O}_{3}$ concentrations are limited to within $300 \mathrm{~m}$ above the surface $(<995 \mathrm{hPa})$ over the urban areas, with the high values over $2.5 \mathrm{ppb}$. The maximum decreases in $\mathrm{O}_{3}$ concentrations occur from the $990 \mathrm{hPa}$ layer to the $860 \mathrm{hPa}$ layer (approximately from 400 to $1500 \mathrm{~m}$ ), and typical reductions are about $0.3 \mathrm{ppb}$. This change pattern in 
winter for Guangzhou is similar to the findings reported in Shanghai and Hangzhou (Xie et al., 2016). But for July the vertical change pattern of $\mathrm{O}_{3}$ above Guangzhou is totally different. As illustrated in Fig. 9d, $\mathrm{O}_{3}$ concentrations decrease at the lower layers, while they increase at the upper levels. The decreases occur from the surface to the $850 \mathrm{hPa}$ layer (about $1.5 \mathrm{~km}$ ), with reduction values of -1 to $-1.5 \mathrm{ppb}$, and the increases appear at the upper layers as well as the surrounding air columns around Guangzhou, with an increment of about $0.9-1.2 \mathrm{ppb}$.

The mechanism of how the AH fluxes influence the spatial and vertical distribution of $\mathrm{O}_{3}$ is more complicated than that for $\mathrm{PM}_{10}$. Only taking into account the physical effects that just impact $\mathrm{O}_{3}$ transport and dispersion into account, we can merely deduce that $\mathrm{O}_{3}$ is seemingly reduced at the surface and may increase at the upper layers because the increase in surface wind speed can facilitate $\mathrm{O}_{3}$ advection transport and the rising up of PBLH can lead to $\mathrm{O}_{3}$ dilution. However, $\mathrm{O}_{3}$ is a secondary air pollutant produced by a series of complex chemical reactions that are also strongly affected by the ambient meteorological conditions. So, the chemical effects can play an important role in $\mathrm{O}_{3}$ changes as well. For example, the increases in air temperature induced by adding $\mathrm{AH}$ can accelerate the $\mathrm{O}_{3}$ production rate. So, the increase in the $\mathrm{O}_{3}$ production rate can directly increase the $\mathrm{O}_{3}$ concentrations near the surface (referred to as the direct chemical effect hereafter). Moreover, because of the $\mathrm{O}_{3}$ sensitivity in the daytime and the $\mathrm{NO}_{x}$ titration at night, $\mathrm{O}_{3}$ formation is inextricably linked with $\mathrm{NO}_{x}$ (referred to as the indirect chemical effect hereafter). As shown in Fig. 10, due mainly to the increases in PBLH and upward air flow caused by adding AH, $\mathrm{NO}_{x}$ can decrease at ground level and increase at the upper layers in both January and July. Then, when the process of $\mathrm{NO}_{x}$ titration dominates the $\mathrm{O}_{3}$ chemistry at night, less $\mathrm{NO}_{x}$ consumes less $\mathrm{O}_{3}$ and leaves more $\mathrm{O}_{3}$ at the surface, while more $\mathrm{NO}_{x}$ consumes more $\mathrm{O}_{3}$ and reduces $\mathrm{O}_{3}$ at the upper layers. For the daytime, because $\mathrm{O}_{3}$ formation is sensitive to VOC over the cities in South China (Xie et al., 2014), the decrease in surface $\mathrm{NO}_{x}$ can lead to a slight increase in $\mathrm{O}_{3}$, while the increase in $\mathrm{NO}_{x}$ at the upper layers can result in the $\mathrm{O}_{3}$ decrease. In January over Guangzhou, these direct and indirect chemical effects should play a more important role in $\mathrm{O}_{3}$ changes than the physical effects, and thereby $\mathrm{O}_{3}$ increases at ground level and decreases at the upper layers. But in July the physical effects should be the governing factor and cause the different pattern of $\mathrm{O}_{3}$ changes in Guangzhou.

In a previous study on $\mathrm{O}_{3}$ variations induced by adding $\mathrm{AH}$, it was found that the vertical changing patterns of $\mathrm{O}_{3}$ over the YRD region in both January and July are always the same as the pattern shown in the winter in Guangzhou (Xie et al., 2016). Comparing the vertical changes in $w$ for July in Guangzhou with those in Shanghai or Hangzhou, we can tell that the AH fluxes can induce stronger upward air movement in the cities of South China, which may be related to their special topographic and climatic features, and thereby more
$\mathrm{O}_{3}$ below the $850 \mathrm{hPa}$ layer is transported to the upper layers or to the surrounding areas of Guangzhou. On the other hand, the rise in air temperature is smaller in Guangzhou than in the YRD cities, so there is no enough produced $\mathrm{O}_{3}$ to compensate for the loss of $\mathrm{O}_{3}$ on the ground. Consequently, impacted by the addition of $\mathrm{AH}, \mathrm{O}_{3}$ decreases at the surface, while it increases at the upper layers in the summer in Guangzhou.

\section{Conclusions}

AH fluxes related to human activities can change the urban circulation and thereby affect the air pollution in and around cities. In this paper, we carry out systematic analyses to study the changes of meteorological conditions induced by $\mathrm{AH}$ and their effects on the concentrations of $\mathrm{PM}_{10}, \mathrm{NO}_{x}$ and $\mathrm{O}_{3}$ in South China. Firstly, the temporal and spatial distribution of $\mathrm{AH}$ emissions is estimated by a top-down energy inventory method. Secondly, the AH parameterization in WRF/Chem is modified to adopt the gridded $\mathrm{AH}$ data with temporal variation. Finally, the WRF/Chem simulations are performed, and the differences between the cases with and without adding $\mathrm{AH}$ are analyzed to quantify the impacts of $\mathrm{AH}$.

The results show that high AH fluxes generally occur in and around cities. In 2014, the regional mean values of AH over Guangdong, Guangxi and Hainan province are 1.68, 0.44 and $0.49 \mathrm{~W} \mathrm{~m}^{-2}$, while the typical values in the urban areas of the PRD region can reach $58.03 \mathrm{~W} \mathrm{~m}^{-2}$. The model results of WRF/Chem fit the observations well. Adding the gridded $\mathrm{AH}$ emissions can better describe the heterogeneous impacts of $\mathrm{AH}$ on regional meteorology and air quality. When AH fluxes are taken into account, the urban heat island and urban-breeze circulations in the big cities are significantly changed. In the PRD city cluster, $2 \mathrm{~m}$ air temperature rises by $1.1^{\circ}$ in January and over $0.5^{\circ}$ in July, the boundary layer height increases by $120 \mathrm{~m}$ in January and $90 \mathrm{~m}$ in July, and $10 \mathrm{~m}$ wind speed is enhanced by over $0.35 \mathrm{~m} \mathrm{~s}^{-1}$ in January and $0.3 \mathrm{~m} \mathrm{~s}^{-1}$ in July. The enhanced vertical movement can transport more moisture to higher levels and causes the accumulative precipitation to increase by $20-40 \%$ over the megacities in July. Influenced by the modifications of meteorological conditions, the spatial and vertical distribution of air pollutants is modified as well. The concentrations of $\mathrm{PM}_{10}$ and $\mathrm{NO}_{x}$ decrease near the surface, while they increase at the upper levels over the big cities in the PRD region; this is mainly related to the higher PBLH, stronger upward air flow and higher surface wind speed. Because the direct chemical effect (the rising up of air temperature directly accelerates surface $\mathrm{O}_{3}$ formation) and the indirect chemical effect (the decrease in $\mathrm{NO}_{x}$ at the ground results in the increase in surface $\mathrm{O}_{3}$ ) play a more important role than the physical effects in winter, the surface $\mathrm{O}_{3}$ concentrations can increase in January with maximum changes over of $2.5 \mathrm{ppb}$ in the megacities. However, in July, the vertical changes in $\mathrm{O}_{3}$ concentrations induced by adding $\mathrm{AH}$ show a different 
pattern, with reductions at the lower layers and increments at the upper layers over Guangzhou. This phenomenon can be attributed to the fact that the physical effects (enhanced upward movement caused by $\mathrm{AH}$ ) become the dominant factor in summer.

There is an important question asked many times by scientists about whether anthropogenic heat emissions contribute to global warming. Although the answers are probably negative, the systematic analyses of $\mathrm{AH}$ over South China in this paper can enhance the understanding of the magnitude of $\mathrm{AH}$ emission from megacities and its impact on regional meteorology and atmospheric chemistry. Compared with the effects from urban land use (Wang et al., 2007; X. M. Wang, 2009; Feng et al., 2012; Chen et al., 2014b; Li et al., 2014; 2016; Liao et al., 2015; Zhu et al., 2015), the impacts of AH are relatively small. Especially in some cities with less air pollution and $\mathrm{AH}$ emissions, such as Haikou, the effects of AH on air quality may be ignored. But our results also clearly show that the meteorology and air pollution predictions in and around big cities are highly sensitive to anthropogenic heat inputs. Thus, for a greater understanding of urban atmospheric environment issues, more studies of anthropogenic heat release in megacities should be considered.

\section{Data availability}

The population density data are available at http://sedac. ciesin.columbia.edu/data/collection/gpw-v4/sets/browse.

The observed meteorological data are accessible from http://data.cma.cn. The air quality monitoring records are available at http://106.37.208.233:20035.

Acknowledgements. This work was supported by the National Natural Science Foundation of China (41475122, 91544230, 41621005), the Key Laboratory of South China Sea Meteorological Disaster Prevention and Mitigation of Hainan Province (SCSF201401), the National Special Fund for Environmental Protection Research in the Public Interest (201409008), and the EU 7th Framework Marie Curie Actions IRSES project REQUA (PIRSES-GA-2013-612671). The authors would like to thank the anonymous reviewers for their constructive and valuable comments on this paper.

Edited by: S. Freitas

Reviewed by: two anonymous referees

\section{References}

Ackermann, I. J., Hass, H., Memmesheimer, M., Ebel, A., Binkowski, F. S., and Shankar, U.: Modal aerosol dynamics model for Europe: Development and first applications, Atmos. Environ., 32, 2981-2999, doi:10.1016/S1352-2310(98)00006-5, 1998.
Akbari, H., Pomerantz, M., and Taha, H.: Cool surfaces and shade trees to reduce energy use and improve air quality in urban areas, Sol. Energy, 70, 295-310, doi:10.1016/S0038-092x(00)00089X, 2001.

Allen, L., Lindberg, F., and Grimmond, C. S. B.: Global to city scale urban anthropogenic heat flux: model and variability, Int. J. Climatol., 31, 1990-2005, doi:10.1002/joc.2210, 2011.

Balzarini, A., Pirovano, G., Honzak, L., Zabkar, R., Curci, G., Forkel, R., Hirtl, M., San Jose, R., Tuccella, P., and Grell, G. A.: WRF-Chem model sensitivity to chemical mechanisms choice in reconstructing aerosol optical properties, Atmos. Environ., 115, 604-619, doi:10.1016/j.atmosenv.2014.12.033, 2015.

Block, A., Keuler, K., and Schaller, E.: Impacts of anthropogenic heat on regional climate patterns, Geophys. Res. Lett., 31, L12211, doi:10.1029/2004g1019852, 2004.

Bohnenstengel, S. I., Hamilton, I., Davies, M., and Belcher, S. E.: Impact of anthropogenic heat emissions on London's temperatures, Q. J. Roy. Meteor. Soc., 140, 687-698, doi:10.1002/qj.2144, 2014.

Chan, C. K. and Yao, X.: Air pollution in mega cities in China, Atmos. Environ., 42, 1-42, doi:10.1016/j.atmosenv.2007.09.003, 2008.

Chen, B., Shi, G. Y., Wang, B., Zhao, J. Q., and Tan, S. C.: Estimation of the anthropogenic heat release distribution in China from 1992 to 2009, Acta Meteorol. Sin., 26, 507-515, doi:10.1007/s13351-012-0409-y, 2012.

Chen, B., Dong, L., Shi, G. Y., Li, L. J., and Chen, L. F.: Anthropogenic Heat Release: Estimation of Global Distribution and Possible Climate Effect, J. Meteorol Soc. Jpn., 92, 157-165, doi:10.2151/jmsj.2014-A10, 2014a.

Chen, B., Yang, S., Xu, X. D., and Zhang, W.: The impacts of urbanization on air quality over the Pearl River Delta in winter: roles of urban land use and emission distribution, Theor. Appl Climatol., 117, 29-39, doi:10.1007/s00704-013-0982-1, 2014b.

Chen, F. and Dudhia, J.: Coupling an advanced land surfacehydrology model with the Penn State-NCAR MM5 modeling system. Part I: Model implementation and sensitivity, Mon. Weather Rev., 129, 569-585, doi:10.1175/15200493(2001)129<0569:Caalsh>2.0.Co;2, 2001.

Chen, F., Kusaka, H., Bornstein, R., Ching, J., Grimmond, C. S. B., Grossman-Clarke, S., Loridan, T., Manning, K. W., Martilli, A., Miao, S. G., Sailor, D., Salamanca, F. P., Taha, H., Tewari, M., Wang, X. M., Wyszogrodzki, A. A., and Zhang, C. L.: The integrated WRF/urban modelling system: development, evaluation, and applications to urban environmental problems, Int. J. Climatol., 31, 273-288, doi:10.1002/joc.2158, 2011.

Chen, Y., Jiang, W. M., Zhang, N., He, X. F., and Zhou, R. W.: Numerical simulation of the anthropogenic heat effect on urban boundary layer structure, Theor. Appl. Climatol., 97, 123-134, doi:10.1007/s00704-008-0054-0, 2009.

Civerolo, K., Hogrefe, C., Lynn, B., Rosenthal, J., Ku, J. Y., Solecki, W., Cox, J., Small, C., Rosenzweig, C., Goldberg, R., Knowlton, K., and Kinney, P.: Estimating the effects of increased urbanization on surface meteorology and ozone concentrations in the New York City metropolitan region, Atmos. Environ., 41, 1803-1818, doi:10.1016/j.atmosenv.2006.10.076, 2007.

Crutzen, P. J.: New Directions: The growing urban heat and pollution "island" effect - impact on chemistry and climate, Atmos. 
Environ., 38, 3539-3540, doi:10.1016/j.atmosenv.2004.03.032, 2004.

Fan, H. L. and Sailor, D. J.: Modeling the impacts of anthropogenic heating on the urban climate of Philadelphia: a comparison of implementations in two PBL schemes, Atmos. Environ., 39, 7384, doi:10.1016/j.atmosenv.2004.09.031, 2005.

Fang, M., Chan, C. K., and Yao, X. H.: Managing air quality in a rapidly developing nation: China, Atmos. Environ., 43, 79-86, doi:10.1016/j.atmosenv.2008.09.064, 2009.

Feng, J. M., Wang, Y. L., Ma, Z. G., and Liu, Y. H.: Simulating the Regional Impacts of Urbanization and Anthropogenic Heat Release on Climate across China, J. Climate, 25, 7187-7203, doi:10.1175/Jcli-D-11-00333.1, 2012.

Feng, J. M., Wang, J., and Yan, Z. W.: Impact of Anthropogenic Heat Release on Regional Climate in Three Vast Urban Agglomerations in China, Adv. Atmos. Sci., 31, 363-373, doi:10.1007/s00376-013-3041-z, 2014.

Ferguson, G. and Woodbury, A. D.: Urban heat island in the subsurface, Geophys. Res. Lett., 34, L23713, doi:10.1029/2007g1032324, 2007.

Flanner, M. G.: Integrating anthropogenic heat flux with global climate models, Geophys. Res. Lett., 36, L02801, doi:10.1029/2008g1036465, 2009.

Grell, G. A. and Devenyi, D.: A generalized approach to parameterizing convection combining ensemble and data assimilation techniques, Geophys. Res. Lett., 29, 1693, doi:10.1029/2002g1015311, 2002.

Grell, G. A., Peckham, S. E., Schmitz, R., McKeen, S. A., Frost, G., Skamarock, W. C., and Eder, B.: Fully coupled "online" chemistry within the WRF model, Atmos. Environ., 39, 6957-6975, doi:10.1016/j.atmosenv.2005.04.027, 2005.

Guenther, A., Karl, T., Harley, P., Wiedinmyer, C., Palmer, P. I., and Geron, C.: Estimates of global terrestrial isoprene emissions using MEGAN (Model of Emissions of Gases and Aerosols from Nature), Atmos. Chem. Phys., 6, 3181-3210, doi:10.5194/acp-63181-2006, 2006.

Hamilton, I. G., Davies, M., Steadman, P., Stone, A., Ridley, I., and Evans, S.: The significance of the anthropogenic heat emissions of London's buildings: A comparison against captured shortwave solar radiation, Build. Environ., 44, 807-817, doi:10.1016/j.buildenv.2008.05.024, 2009.

Iamarino, M., Beevers, S., and Grimmond, C. S. B.: High-resolution (space, time) anthropogenic heat emissions: London 1970-2025, Int. J. Climatol., 32, 1754-1767, doi:10.1002/joc.2390, 2012.

Ichinose, T., Shimodozono, K., and Hanaki, K.: Impact of anthropogenic heat on urban climate in Tokyo, Atmos. Environ., 33, 3897-3909, doi:10.1016/S1352-2310(99)00132-6, 1999.

Janjic, Z. I.: The Step-Mountain Eta Coordinate Model - Further Developments Of the Convection, Viscous Sublayer, And Turbulence Closure Schemes, Mon. Weather Rev., 122, 927-945, doi:10.1175/1520-0493(1994)122<0927:Tsmecm>2.0.Co;2, 1994.

Jiang, X. Y., Wiedinmyer, C., Chen, F., Yang, Z. L., and Lo, J. C. F.: Predicted impacts of climate and land use change on surface ozone in the Houston, Texas, area, J. Geophys. Res.-Atmos., 113, D20312, doi:10.1029/2008jd009820, 2008.

Kim, H. J. and Wang, B.: Sensitivity of the WRF Model Simulation of the East Asian Summer Monsoon in 1993 to Shortwave Radi- ation Schemes and Ozone Absorption, Asia-Pac. J. Atmos. Sci., 47, 167-180, doi:10.1007/s13143-011-0006-y, 2011.

Lee, S. H., Song, C. K., Baik, J. J., and Park, S. U.: Estimation of anthropogenic heat emission in the Gyeong-In region of Korea, Theor. Appl. Climatol., 96, 291-303, doi:10.1007/s00704-0080040-6, 2009.

Li, M. M., Song, Y., Huang, X., Li, J. F., Mao, Y., Zhu, T., Cai, X. H., and Liu, B.: Improving mesoscale modeling using satellite-derived land surface parameters in the Pearl River Delta region, China, J. Geophys. Res.-Atmos., 119, 6325-6346, doi:10.1002/2014JD021871, 2014.

Li, M. M., Song, Y., Mao, Z. C., Liu, M. X., and Huang, X.: Impacts of thermal circulations induced by urbanization on ozone formation in the Pearl River Delta region, China, Atmos. Environ., 127, 382-392, doi:10.1016/j.atmosenv.2015.10.075, 2016.

Liao, J. B., Wang, T. J., Jiang, Z. Q., Zhuang, B. L., Xie, M., Yin, C. Q., Wang, X. M., Zhu, J. L., Fu, Y., and Zhang, Y.: WRF/Chem modeling of the impacts of urban expansion on regional climate and air pollutants in Yangtze River Delta, China, Atmos. Environ., 106, 204-214, doi:10.1016/j.atmosenv.2015.01.059, 2015.

Lin, Y. L., Farley, R. D., and Orville, H. D.: Bulk Parameterization Of the Snow Field In a Cloud Model, J. Clim. Appl. Meteorol., 22, 1065-1092, doi:10.1175/15200450(1983)022<1065:Bpotsf>2.0.Co;2, 1983.

Liu, M., Wang, H., Wang, H., Oda, T., Zhao, Y., Yang, X., Zang, R., Zang, B., Bi, J., and Chen, J.: Refined estimate of China's $\mathrm{CO}_{2}$ emissions in spatiotemporal distributions, Atmos. Chem. Phys., 13, 10873-10882, doi:10.5194/acp-13-10873-2013, 2013.

Liu, Q., Lam, K. S., Jiang, F., Wang, T. J., Xie, M., Zhuang, B. L., and Jiang, X. Y.: A numerical study of the impact of climate and emission changes on surface ozone over South China in autumn time in 2000-2050, Atmos. Environ., 76, 227-237, doi:10.1016/j.atmosenv.2013.01.030, 2013.

Lo, J. C. F., Lau, A. K. H., Chen, F., Fung, J. C. H., and Leung, K. K. M.: Urban modification in a mesoscale model and the effects on the local circulation in the Pearl River Delta region, J. Appl. Meteorol. Clim., 46, 457-476, doi:10.1175/Jam2477.1, 2007.

Lu, X., Chow, K. C., Yao, T., Lau, A. K. H., and Fung, J. C. H.: Effects of urbanization on the land sea breeze circulation over the Pearl River Delta region in winter, Int. J. Climatol., 30, 10891104, doi:10.1002/joc.1947, 2010.

Lu, Y., Wang, Q. G., Zhang, Y. Y., Sun, P., and Qian, Y.: An estimate of anthropogenic heat emissions in China, Int. J. Climatol., 36, 1134-1142, doi:10.1002/joc.4407, 2016.

Madronich, S.: Photodissociation In the Atmosphere .1. Actinic Flux And the Effects Of Ground Reflections And Clouds, J. Geophys. Res.-Atmos., 92, 9740-9752, doi:10.1029/Jd092id08p09740, 1987.

Menberg, K., Bayer, P., Zosseder, K., Rumohr, S., and Blum, P.: Subsurface urban heat islands in German cities, Sci. Total Environ., 442, 123-133, doi:10.1016/j.scitotenv.2012.10.043, 2013.

Meng, W. G., Zhang, Y. X., Li, J. N., Lin, W. S., Dai, G. F., and $\mathrm{Li}, \mathrm{H}$. R.: Application Of Wrf/Ucm In the Simulation Of a Heat Wave Event And Urban Heat Island around Guangzhou, J. Trop. Meteorol., 17, 257-267, doi:10.3969/j.issn.10068775.2011.03.007, 2011.

Mirzaei, P. A. and Haghighat, F.: Approaches to study Urban Heat Island - Abilities and limitations, Build. Environ., 45, 2192 2201, doi:10.1016/j.buildenv.2010.04.001, 2010. 
Mlawer, E. J., Taubman, S. J., Brown, P. D., Iacono, M. J., and Clough, S. A.: Radiative transfer for inhomogeneous atmospheres: RRTM, a validated correlated-k model for the longwave, J. Geophys. Res.-Atmos., 102, 16663-16682, doi:10.1029/97jd00237, 1997.

Oke, T. R.: The Urban Energy-Balance, Prog. Phys. Geog., 12, 471508, doi:10.1177/030913338801200401, 1988.

Pigeon, G., Legain, D., Durand, P., and Masson, V.: Anthropogenic heat release in an old European agglomeration (Toulouse, France), Int. J. Climatol., 27, 1969-1981, doi:10.1002/joc.1530, 2007

Quah, A. K. L. and Roth, M.: Diurnal and weekly variation of anthropogenic heat emissions in a tropical city, Singapore, Atmos. Environ., 46, 92-103, doi:10.1016/j.atmosenv.2011.10.015, 2012

Rizwan, A. M., Dennis, Y. C. L., and Liu, C. H.: A review on the generation, determination and mitigation of Urban Heat Island, J. Environ. Sci.-China, 20, 120-128, doi:10.1016/S10010742(08)60019-4, 2008

Ryu, Y. H., Baik, J. J., and Lee, S. H.: Effects of anthropogenic heat on ozone air quality in a megacity, Atmos. Environ., 80, 20-30, doi:10.1016/j.atmosenv.2013.07.053, 2013.

Sailor, D. J. and Lu, L.: A top-down methodology for developing diurnal and seasonal anthropogenic heating profiles for urban areas, Atmos. Environ., 38, 2737-2748, doi:10.1016/j.atmosenv.2004.01.034, 2004.

Schell, B., Ackermann, I. J., Hass, H., Binkowski, F. S., and Ebel, A.: Modeling the formation of secondary organic aerosol within a comprehensive air quality model system, J. Geophys. Res.Atmos., 106, 28275-28293, doi:10.1029/2001jd000384, 2001.

Stockwell, W. R., Middleton, P., Chang, J. S., and Tang, X. Y.: The 2nd Generation Regional Acid Deposition Model Chemical Mechanism for Regional Air-Quality Modeling, J. Geophys. Res.-Atmos., 95, 16343-16367, doi:10.1029/Jd095id10p16343, 1990.

Stone, B.: Urban sprawl and air quality in large US cities, J. Environ. Manage., 86, 688-698, doi:10.1016/j.jenvman.2006.12.034, 2008.

Wang, T., Wei, X. L., Ding, A. J., Poon, C. N., Lam, K. S., Li, Y. S., Chan, L. Y., and Anson, M.: Increasing surface ozone concentrations in the background atmosphere of Southern China, 19942007, Atmos. Chem. Phys., 9, 6217-6227, doi:10.5194/acp-96217-2009, 2009.

Wang, X. M., Lin, W. S., Yang, L. M., Deng, R. R., and Lin, H.: A numerical study of influences of urban land-use change on ozone distribution over the Pearl River Delta region, China, Tellus B, 59, 633-641, doi:10.1111/j.1600-0889.2007.00271.x, 2007.

Wang, X. M., Chen, F., Wu, Z. Y., Zhang, M. G., Tewari, M., Guenther, A., and Wiedinmyer, C.: Impacts of Weather Conditions Modified by Urban Expansion on Surface Ozone: Comparison between the Pearl River Delta and Yangtze River Delta Regions, Adv. Atmos. Sci., 26, 962-972, doi:10.1007/s00376-009-80012, 2009.

Wang, X. M., Liao, J. B., Zhang, J., Shen, C., Chen, W. H., Xia, B. C., and Wang, T. J.: A Numeric Study of Regional Climate Change Induced by Urban Expansion in the Pearl River Delta, China, J. Appl. Meteorol. Clim., 53, 346-362, 2014.
World Bank Group: East Asia's changing urban landscape: measuring a decade of spatial growth, World Bank, Washington DC, 2015.

Wu, J. B., Chow, K. C., Fung, J. C. H., Lau, A. K. H., and Yao, T.: Urban heat island effects of the Pearl River Delta city clusterstheir interactions and seasonal variation, Theor. Appl. Climatol., 103, 489-499, doi:10.1007/s00704-010-0323-6, 2011.

Wu, K. and Yang, X. Q.: Urbanization and heterogeneous surface warming in eastern China, Chinese Sci. Bull., 58, 1363-1373, doi:10.1007/s11434-012-5627-8, 2013.

Xie, M., Zhu, K. G., Wang, T. J., Yang, H. M., Zhuang, B. L., Li, S., Li, M. G., Zhu, X. S., and Ouyang, Y.: Application of photochemical indicators to evaluate ozone nonlinear chemistry and pollution control countermeasure in China, Atmos. Environ., 99, 466-473, doi:10.1016/j.atmosenv.2014.10.013, 2014.

Xie, M., Zhu, K. G., Wang, T. J., Feng, W., Zhu, X. S., Chen, F., Ouyang, Y., and Liu, Z. J.: Study on the distribution of anthropogenic heat flux over China, China Environmental Science, 35, 728-734, 2015.

Xie, M., Liao, J., Wang, T., Zhu, K., Zhuang, B., Han, Y., Li, M., and Li, S.: Modeling of the anthropogenic heat flux and its effect on regional meteorology and air quality over the Yangtze River Delta region, China, Atmos. Chem. Phys., 16, 6071-6089, doi:10.5194/acp-16-6071-2016, 2016.

Yu, M., Carmichael, G. R., Zhu, T., and Cheng, Y. F.: Sensitivity of predicted pollutant levels to anthropogenic heat emissions in Beijing, Atmos. Environ., 89, 169-178, doi:10.1016/j.atmosenv.2014.01.034, 2014.

Zhang, D. L., Shou, Y. X., and Dickerson, R. R.: Upstream urbanization exacerbates urban heat island effects, Geophys. Res. Lett., 36, L24401, doi:10.1029/2009g1041082, 2009.

Zhang, Q., Streets, D. G., Carmichael, G. R., He, K. B., Huo, H., Kannari, A., Klimont, Z., Park, I. S., Reddy, S., Fu, J. S., Chen, D., Duan, L., Lei, Y., Wang, L. T., and Yao, Z. L.: Asian emissions in 2006 for the NASA INTEX-B mission, Atmos. Chem. Phys., 9, 5131-5153, doi:10.5194/acp-9-5131-2009, 2009.

Zhang, Y. N., Xiang, Y. R., Chan, L. Y., Chan, C. Y., Sang, X. F., Wang, R., and Fu, H. X.: Procuring the regional urbanization and industrialization effect on ozone pollution in Pearl River Delta of Guangdong, China, Atmos. Environ., 45, 4898-4906, doi:10.1016/j.atmosenv.2011.06.013, 2011.

Zheng, J. Y., Zhang, L. J., Che, W. W., Zheng, Z. Y., and Yin, S. S.: A highly resolved temporal and spatial air pollutant emission inventory for the Pearl River Delta region, China and its uncertainty assessment, Atmos. Environ., 43, 5112-5122, doi:10.1016/j.atmosenv.2009.04.060, 2009.

Zhu, K., Blum, P., Ferguson, G., Balke, K. D., and Bayer, P.: The geothermal potential of urban heat islands, Environ. Res. Lett., 5, 044002, doi:10.1088/1748-9326/5/4/044002, 2010.

Zhu, B., Kang, H. Q., Zhu, T., Su, J. F., Hou, X. W., and Gao, J. H.: Impact of Shanghai urban land surface forcing on downstream city ozone chemistry, J. Geophys. Res.-Atmos., 120, 4340-4351, doi:10.1002/2014JD022859, 2015. 